\title{
DE LA POBREZA A LA EXCLUSIÓN SOCIAL. Nuevos retos para las políticas públicas*
}

\author{
QUIM BRUGUÉ, RICARD GOMÀ y JOAN SUBIRATS \\ Institut de Govern i Polítiques Públiques. Universidad Autónoma de Barcelona
}

PALABRAS ClaVe Adicionales

Pobreza, Exclusión social, Políticas públicas.
ADDITIONAL KEYWORDS

Poverty, Social Exclusion, Public Policies.

\begin{abstract}
RESUMEN. El presente artículo pretende abordar el tema de la exclusión social. Para ello, se estructura en tres grandes bloques. En el primero, el bloque conceptual, se discuten el potencial y los límites del concepto de exclusión social y el conjunto de factores que operan como motores generadores de procesos de exclusión. En el segundo, el bloque de vocación más descriptiva, se exponen algunos datos sobre el alcance y los perfiles que toman hoy de forma predominante los procesos de exclusión. En el tercero, el bloque de las políticas, se muestra el abanico de respuestas institucionales a escala europea y española. Se aprecia aquí el sesgo de las políticas hacia el frente de la pobreza, y las dificultades para articular verdaderas estrategias públicas para la inclusión social. El artículo se completa con algunos elementos de propuesta, y unas reflexiones finales de síntesis y conclusión.
\end{abstract}

SUMMARY. This article deals with social exclusion. It is organized around three main parts. Firstly, in the conceptual framework, we discuss the Potential and limits of the concept of social exclusion, as well as the set of factors which operated as driving forces of the processes of exclusion in the post-industrial society. Secondly, some Sapnish and comparative data are brought together, in order to show both the extent and the profiles which shape today social exclusion. Finally, the wide policy agenda to fight against social exclusion is taken into account. Here we appreciate the policy bias towards poverty, and the big difficulties to build up more comprehensive policies for social inclusion. The article comes to an end with some proposals and elements of conclusion.

\footnotetext{
*Este artículo se enmarca en un proceso más amplio de trabajo del Institut de Govern i Polítiques Públiques sobre exclusión social, en el que participan también Jaume Badosa, Laura Giménez, Gemma Laumandreu, Aida Jiménez, Marc Martí, Anna Obradors, Natalia Rosetti y Gemma Ubasart. Las reflexiones que se desgranan en este texto son el resultado del trabajo y del debate conjunto. Vaya pues por delante nuestro reconocimiento al trabajo de todo el equipo.

E-mail: ricard.goma@uab.es
}

Revista Internacional de Sociología (RIS)
Tercera Época, $\mathrm{n}^{\circ}$ 33, Septiembre-Diciembre, 2002, pp. 7-45.




\section{CONSIDERACIONES INTRODUCTORIAS}

Los principales parámetros socioeconómicos y culturales que fundamentaron durante más de medio siglo la sociedad industrial están quedando atrás. Asistimos a una época de transformaciones de fondo y a gran velocidad: los vectores de cambio, en cualquier dimensión de la realidad, predominan sobre los factores de estabilidad. Los instrumentos de ánalisis y reflexión que apoyaron nuestra interpretación del estado fordista y keynesiano de bienestar cada vez resultan más obsoletos. Repasemos muy brevemente las dimensiones del cambio social en marcha, como requisito para sostener la necesidad de desbordar el concepto clásico de pobreza hacia la idea compleja y emergente de exclusión social.

Desde el punto de vista productivo, el impacto de los grandes cambios tecnológicos ha modificado totalmente las coordenadas del industrialismo. Se han superado las estructuras fordistas, aquellas en las que grandes concentraciones de trabajadores eran capaces de producir ingentes cantidades de productos de consumo masivo a precios asequibles, sobre la base de una organización del trabajo taylorista y a costa de una notable homogeneidad en la gama de bienes producidos. La llamada globalización o mundialización económica, construida sobre la base de la revolución en los sistema de información, ha permitido avanzar hacia un mercado mundial, en el que las distancias cuentan menos, y donde el aprovechamiento de los costes diferenciales a escala planetaria ha desarticulado empresas y plantas de producción. Palabras como flexibilización, adaptabilidad o movilidad han reemplazado a especialización, estabilidad o continuidad (Gallie y Paugan, 2000). La sociedad del conocimiento busca el valor diferencial, la fuente del beneficio y de la productividad en el capital intelectual frente a las lógicas anteriores centradas en el capital físico y humano.

Incluso más allá, como ha señalado Ulrich Beck (2002), lo que está en juego es la propia concepción del trabajo como elemento estructurante de la vida, de la inserción y del conjunto de relaciones sociales. Y, en este sentido, las consecuencias más inmediatas de esa reconsideración del trabajo afectan en primer lugar a lo que podríamos denominar la propia calidad del trabajo disponible (Goul y Gensen, 2002). Lo que se ha llamado brasileñización del empleo, trata de describir la creciente precarización de los puestos de trabajo disponibles o creados en estos últimos años en Europa. Si en los años 60, sólo un 10\% de los puestos de trabajo en Alemania podían ser considerados como precarios, ese porcentaje se dobló en los setenta, alcanzando ya en los 90 a un tercio de los trabajos realmente existentes. Y la tendencia sigue imparable. Sólo consideramos como trabajo un conjunto de labores que van precarizándose y que tienden a reducirse cada día que pasa, y mientras, otras muchas cosas que hacemos, socialmente útiles, las seguimos considerando como no trabajo. ¿Podemos seguir manteniendo una concepción del trabajo estrechamente vinculada a labores productivas y salarialmente reconocidas? En definitiva, el capital se nos ha hecho global y permanentemente 
movilizable y movilizado, mientras el trabajo sólo es local, y cada vez es menos permanente, más condicionado por la volatilidad del espacio productivo.

Desde el punto de vista de la estructura social, la sociedad industrial nos había acostumbrado a estructuras relativamente estables y previsibles. Hemos asistido en poco tiempo a una acelerada transición desde esa sociedad hacia una realidad compleja, caracterizada por una multiplicidad de ejes cambiantes de desigualdad. $\mathrm{Si}$ antes las situaciones problemáticas se concentraban en sectores sociales que disponían de mucha experiencia histórica acumulada al respecto, y que habían ido desarrollando respuestas, ahora el riesgo se ha democratizado, castigando más severamente a los de siempre, pero golpeando también a nuevas capas y personas (Edwards y Glover, 2001). Aparecen, es cierto, nuevas posibilidades de ascenso y movilidad social que antes eran mucho más episódicas. Encontramos más niveles y oportunidades de riqueza en segmentos o núcleos sociales en los que antes sólo existía continuidad de carencia. Pero hallamos también, por otro lado, nuevos e inéditos espacios de pobreza y de dificultad en el sobrevivir diario. Frente a la anterior estructura social de grandes agregados y de importantes continuidades, tenemos hoy un mosaico cada vez más fragmentado de situaciones de pobreza, de riqueza, de fracaso y de éxito. Pero, mientras la miseria coloniza, la riqueza expulsa. Y ello genera una proliferación de riesgos y de interrogantes que provoca fenómenos de búsqueda de certezas en la segmentación social y territorial. Los que pueden buscan espacios territoriales o institucionales donde encontrarse seguros con los "suyos", cerrando las puertas a los "otros" (Bomnes y Geddens, 2000).

Desde el punto de vista de las relaciones de familia y de género, los cambios no son menores. El ámbito de convivencia primaria no presenta ya el mismo aspecto que tenía en la época industrial. Los hombres trabajaban fuera del hogar, mientras las mujeres asumían sus responsabilidades reproductoras, cuidando marido, hijos y ancianos. Las mujeres no precisaban formación específica y su posición era dependendiente económica y socialmente. El escenario es hoy muy distinto. La equiparación formativa entre hombres y mujeres es muy alta y la incorporación de las mujeres al mundo laboral aumenta sin cesar, a pesar de las evidentes discriminaciones que se mantienen. Pero, al lado de lo muy positivos que resultan esos cambios para devolver a las mujeres toda su dignidad personal, lo cierto es que los roles en el seno del hogar apenas si se han modificado (Tortosa, 2001). Crecen las tensiones por la doble jornada laboral de las mujeres, se incrementan las separaciones y aumentan también las familias en las que sólo la mujer cuida de los hijos (Sainsbury, 1999). Y, con todo ello, se provocan nuevas inestabilidades sociales, nuevos filones de exclusión, en los que la variable género resulta determinante.

Ese conjunto de cambios y de profundas transformaciones en las esferas productiva, social y familar no se han encontrado con los poderes públicos en su mejor momento. Los retos son nuevos y difíciles de abordar, y las administraciones públicas no tienen la agilidad para darles respuestas adecuadas. El mercado se 
ha globalizado, el poder político sigue en buena parte anclado al territorio; y es en ese territorio donde los problemas se manifiestan diariamente. La fragmentación institucional aumenta, perdiendo peso el Estado hacia arriba (instituciones supraestatales), hacia abajo (procesos de descentralización, devolution, etc.), y hacia los lados (con un gran incremento de los partenariados públicos-privados, con gestión privada de servicios públicos, y con presencia cada vez mayor de organizaciones sin ánimo de lucro presentes en el escenario público). Al mismo tiempo, la lógica jerárquica que ha caracterizado siempre el ejercicio del poder no sirve hoy para entender los procesos de decisión pública, basados cada vez más en lógicas de interdependencia, de capacidad de influencia, de poder relacional, y cada vez menos en estatuto orgánico o en ejercicio de jerarquía formal (Kickert, 1997).

En ese contexto institucional, las políticas públicas que fueron concretando la filosofía del Estado del bienestar, se han ido volviendo poco operativas, poco capaces de incorporar las nuevas demandas, las nuevas sensibilidades, o tienen una posición débil ante nuevos problemas. Las políticas de bienestar se construyeron desde lógicas de respuesta a demandas que se presumían homogéneas y diferenciadas, y se gestionaron de manera rígida y burocrática. Mientras hoy tenemos un escenario en el que las demandas, por las razones apuntadas más arriba, son cada vez más heterogéneas, llenas de multiplicidad en su forma de presentarse, y sólo pueden ser abordadas desde formas de gestión flexibles y desburocratizadas.

Este contexto complejo y lleno de preguntas sin respuesta es el nuevo marco en el que se inscribe el concepto de exclusión social. Concepto que engloba a la pobreza pero va más allá; la exclusión social se define también por la imposibilidad o dificultad intensa de acceder a los mecanismos de desarrollo personal e inserción socio-comunitaria y a los sistemas preestablecidos de protección. La existencia de sectores socialmente excluidos, en el marco de las nuevas sociedades posindustriales es una realidad ampliamente asumida (Saraceno, 2002). Sin embargo, los niveles concretos de conocimiento sobre esta realidad están todavía hoy claramente por debajo de lo deseable. Como suele suceder en tiempos de cambios acelerados, la dispersión de conceptos y discursos no siempre encuentra apoyos sólidos en el campo de la reflexión sosegada y del desarrollo de instrumentos de conocimiento empírico (Barnes et al., 2002)

\section{POTENCIAL Y LÍMITES DEL CONCEPTO DE EXCLUSIÓN SOCIAL}

Hay un cierto acuerdo en la literatura académica y en la práctica social en destacar el potencial descriptivo y la riqueza teórico-analítica de la noción de exclusión social. Nuestro objetivo es ahora reflexionar en torno a los componentes clave que confluyen en el concepto. 


\section{La exclusión como fenómeno estructural}

La exclusión social, como realidad de hecho, no es algo básicamente nuevo. Puede inscribirse en la trayectoria histórica de las desigualdades sociales. Con antecedentes claros -en el marco histórico de las sociedades contemporáneas- en forma de necesidades colectivas intensas, en otros muchos momentos y lugares, desde el inicio de los procesos de industrialización y urbanización masiva, durante los siglos XIX y XX. Ahora bien, la exclusión social expresa la nueva configuración de las desigualdades en el contexto actual de transición hacia la sociedad del conocimiento. La cuestión social se transforma y adquiere una nueva naturaleza en las emergentes sociedades tecnológicas avanzadas. La exclusión social es, en buena parte, el reflejo de esa naturaleza (Gil, 2002) ¿Qué hay entonces de nuevo ? Muy en síntesis, la vieja sociedad industrial en su fase madura presenta polarizaciones unidimensionales, lineales, generadas por la lógica de clase, que no llegan a romper los parámetros básicos de la integración social. La exclusión, en un contexto de creciente heterogeneidad, no implica sólo la reproducción más o menos ampliada de las desigualdades verticales del modelo industrial. Va más allá, la exclusión implica fracturas en el tejido social y la ruptura de ciertas coordenadas básicas de integración. En consecuencia, la aparición de una nueva escisión social en términos de dentro / fuera; generadora, por tanto, de un nuevo sociograma de colectivos excluidos.

\section{La exclusión como fenómeno dinámico}

La exclusión es mucho más un proceso - o un conjunto de procesos- que una situación estable. Dichos procesos presentan una geometría variable; es decir, no afectan sólo a grupos predeterminados concretos, más bien al contrario, afectan de forma cambiante a personas y colectivos, a partir de las modificaciones que pueda sufrir la función de vulnerabilidad de éstos frente a dinámicas de marginación (Tezanos, 1999). La distribución de riesgos sociales -en un contexto marcado por la erosión progresiva de los anclajes de seguridad de la modernidad industrial-se vuelve mucho más compleja y generalizada. El riesgo de ruptura familiar en un contexto de cambio en las relaciones de género, el riesgo de descualificación en un marco de cambio tecnológico acelerado, el riesgo de precariedad e infrasalarización en un contexto de cambio en la naturaleza del vínculo laboral..., todo ello y otros muchos ejemplos, pueden trasladar hacia zonas de vulnerabilidad la exclusión a personas y colectivos variables, en momentos muy diversos de su ciclo de vida. Las fronteras de la exclusión son móviles y fluidas; los índices de riesgo presentan extensiones sociales e intensidades personales altamente cambiantes (Atkinson et al., 2002). 
R I S

\section{La exclusión como fenómeno multifactorial y multidimensional}

La exclusión social no se explica con arreglo a una sola causa. Ni tampoco sus desventajas vienen solas: se presenta en cambio como un fenómeno poliédrico, formado por la articulación de un cúmulo de circunstancias desfavorables, a menudo fuertemente interrelacionadas. En el apartado siguiente consideraremos los varios factores que anidan en las raíces de la exclusión. Cabe destacar ahora su carácter complejo, formado por múltiples vertientes. La exclusión dificilmente admite definiciones segmentadas. Una sencilla explotación de las estadísticas nos muestra las altísimas correlaciones entre, por ejemplo, fracaso escolar, precariedad laboral, desprotección social, monoparentalidad y género. $\mathrm{O}$ bien entre barrios guetizados, infravivienda, segregación étnica, pobreza y sobreincidencia de enfermedades. Todo ello conduce hacia la imposibilidad de un tratamiento unidimensional y sectorial de la exclusión social. La marginación, como temática de agenda pública, requiere abordajes integrales en su definición, y horizontales o transversales en sus procesos de gestión (Percy-Smith, 2000).

\section{La exclusión como fenómeno politizable}

La exclusión social no está inscrita de forma fatalista en el destino de ninguna sociedad. Como no lo está ningún tipo de desigualdad o marginación. Al contrario, la exclusión es susceptible de ser abordada desde los valores, desde la acción colectiva, desde la práctica institucional y desde las políticas públicas. Más aún, en cada sociedad concreta, las mediaciones políticas y colectivas sobre la exclusión se convierten en uno de sus factores explicativos clave. ¿Por qué creemos que es importante hacer hincapié en todo esto? En otros momentos históricos, por ejemplo en las etapas centrales de la sociedad industrial, el colectivo sometido a relaciones de desigualdad y subordinación había adquirido subjetividad propia y, por tanto, capacidad de autoorganización social y política. Se había convertido en agente portador de un modelo alternativo, con potencial de superación de las relaciones de desigualdad vigentes. Ello no pasa con la exclusión. Los colectivos marginados no conforman ningún sujeto homogéneo y articulado de cambio histórico, visible y con capacidad de superación de la exclusión (Pierson, 2002). De ahí que sea mucho más complicado generar procesos de movilización y definir una praxis superadora de la exclusión. De ahí también que a menudo se cuestione la posibilidad de mediaciones políticas emancipatorias sobre la exclusión. Y se imponga con facilidad, en cambio, una cierta perspectiva cultural que lleva a considerar la exclusión como algo inherente a las sociedades avanzadas del siglo XXI. 


\section{LOS FACTORES DE LA EXCLUSIÓN SOCIAL}

En el terreno conceptual, la idea de síntesis pasaría por considerar la exclusión social como un fenómeno cambiante, relacional, insertado en el marco de las transformaciones hacia sociedades postindustriales y susceptible de mediaciones politicas colectivas. Sobre esta base, el siguiente paso debería ser la identificación de los grandes factores generadores de exclusión. En concreto, proponemos optar por el análisis de tres mecanismos que operan, creemos, como determinantes clave de la magnitud y estructura de la exclusión en las sociedades postindustriales.

\section{La fragmentación tridimensional de la sociedad}

Cabe destacar, en primer lugar, la transición hacia una estructura social mucho más compleja y fragmentada, caracterizada por lo menos en tres planos: a) $l a$ diversificación étnica derivada de emigraciones de los paises empobrecidos, generadora - a falta de políticas potentes de interculturalidad- de un escenario de precarización múltiple (legal, económica, relacional y familiar) de un buen número de colectivos inmigrantes; b) la alteración de la pirámide de edades, con incremento de las tasas de dependencia demográfica, a menudo ligadas a estados de dependencia física; y c) la pluralidad de formas de convivencia familiar con incremento de la monoparentalidad en capas populares. La erosión del modelo patriarcal, junto a la debilidad de las políticas de educación infantil y de atención a la vejez, junto a las aún fuertes dificultades de articulación entre familia y empleo de calidad, propician nuevas dinámicas de riesgo social en amplios colectivos de mujeres (Österle, 2001; Lewis, 1998)

\section{El impacto sobre el empleo de la economía posindustrial}

Cabe considerar, en segundo lugar, el impacto que sobre el mercado de trabajo, el empleo y las relaciones laborales desencadena la transición hacia el modelo de economía informacional con esquemas de producción posfordistas. Desde luego, los impactos son múltiples y en muchas direcciones. Para sectores relevantes de la sociedad, el cambio económico puede haber generado un abanico de nuevas oportunidades, impensable en periodos anteriores. Pero no podemos obviar que todo cambio económico, inscrito en la lógica del capitalismo, genera perdedores históricos. En este caso, perdedores empujados hacia procesos de exclusión, plasmados en nuevas realidades conectadas a la esfera laboral: desempleo juvenil de nuevo tipo, estructural y adulto de larga duración; trabajos de baja calidad sin vertiente formativa; y empleos de salario muy bajo y sin cobertura por convenio colectivo (Considine, 2001). Todo ello nos remite y puede sintetizarse en dos fenómenos: 


\section{RIS}

a) Las trayectorias lineales y rápidas de los jóvenes hacia el empleo industrial asalariado son hoy residuales. Han dado paso a un abanico de itinerarios muy complejos y dilatados en el tiempo. Los itinerarios de inserción recorridos por jóvenes con intensas carencias formativas y débiles resortes de aprendizaje, que dan acceso estricto a empleos eventuales, precarios y no generadores de ningún tipo de vínculo grupal o comunitario, construyen unas condiciones propicias para un nuevo espacio de exclusión social juvenil.

b) La irreversible flexibilidad de los procesos productivos en la economía informacional ha servido de argumento, en algunas sociedades, entre ellas la española, para impulsar procesos paralelos de destrucción de empleo y de desregulación laboral, con erosión de derechos laborales y debilitamiento de los esquemas de protección social tradicionalmente ligados al mercado de trabajo. Ello ha generado nuevos espacios sociales de exclusión, que afectan no sólo a la población más joven, sino también y sobre todo a colectivos adultos con cargas familiares.

\section{El déficit de inclusividad del Estado de bienestar}

Finalmente, puede sostenerse que el déficit de inclusividad del Estado de bienestar opera como un tercer factor clave, y lo hace en un mínimo de dos planos. Se han ido consolidando, por una parte, fracturas de ciudadania a partir del diseño poco inclusivo y en ocasiones del fracaso implementador de las principales políticas clásicas de bienestar: por ejemplo, la exclusión de la seguridad social de grupos con insuficiente vinculación al mecanismo contributivo, o la exclusión de sectores vulnerables al fracaso escolar en la enseñanza pública de masas. Se ha ido incrementando, por otra parte, el carácter segregador de ciertos mercados de bienestar con una presencia pública muy débil: por ejemplo, los mercados del suelo e inmobiliario. Hecho que provoca la exclusión del acceso a la vivienda de amplios colectivos sociales y pautas de fractura social en el territorio (Harrison, Davis, 2001).

Desde luego, la fragmentación de la sociedad, el impacto sobre la esfera laboral de la economía postindustrial y los déficit de inclusividad de las políticas clásicas de bienestar no operan de forma aislada entre sí. Se interrelacionan y, a menudo, se potencian mutuamente. De hecho, las dinámicas de exclusión social se desarrollan al calor de estas interrelaciones. Ciertos colectivos inmigrantes, por ejemplo, no sólo ocupan las posiciones más marginales en la división étnica del trabajo, sino que padecen también obstáculos de acceso a los sistemas de protección social, y son muy vulnerables a la discriminación en el mercado de la vivienda. Sectores de población dependiente, de edad avanzada, quedan con facilidad excluidos de unos servicios sociales con tasas muy bajas de cobertura. $\mathrm{O}$ bien, comunidades que habitan barrios periféricos segregados sufren con mayor intensidad el desempleo de larga duración o una precaria inserción laboral. En definitiva, se plasma el carácter multifactorial y multidimensional de la exclusión en la realidad (CES, 1997). 
La tabla 1 pretende mostrar de forma gráfica y esquematizada los factores generadores de exclusión social. Tiende además un puente hacia los apartados siguientes del capítulo, al poner en conexión dichos procesos con algunos de los principales colectivos vulnerables a la exclusión y con los sectores de política pública ensayados como respuesta.

Tabla 1.

Exclusión Social. Factores, Grupos Sociales y Politicas

\begin{tabular}{|c|c|c|}
\hline $\begin{array}{l}\text { FACTORES DE } \\
\text { EXCLUSIÓN }\end{array}$ & $\begin{array}{l}\text { COLECTIVOS } \\
\text { EXCLUIDOS }\end{array}$ & $\begin{array}{l}\text { POLÍTICAS FRENTE } \\
\text { A LA EXCLUSIÓN }\end{array}$ \\
\hline $\begin{array}{l}\text { Economía postindustrial } \\
\text { e impacto sobre el empleo }\end{array}$ & $\begin{array}{l}\text { Jóvenes con dificultades } \\
\text { intensas de inserción laboral } \\
\text { Adultos desempleados de } \\
\text { larga duración }\end{array}$ & $\begin{array}{c}\text { Políticas contra el } \\
\text { paro juvenil y el } \\
\text { desempleo de larga } \\
\text { duración }\end{array}$ \\
\hline $\begin{array}{l}\text { Inmigraciones del Sur hacia UE } \\
\text { Nuevos modelos familiares } \\
\text { Nueva estructura demográfica }\end{array}$ & $\begin{array}{l}\text { Colectivos de inmigrantes } \\
\text { Mujeres-madres solas } \\
\text { Gente mayor dependiente }\end{array}$ & $\begin{array}{l}\text { Políticas de Rentas } \\
\text { mínimas }\end{array}$ \\
\hline $\begin{array}{l}\text { Sistemas de protección } \\
\text { social contributivos } \\
\text { Sistemas Beveridge de } \\
\text { protección social con } \\
\text { coberturas no universales } \\
\text { Servicios sociales insuficientes }\end{array}$ & $\begin{array}{l}\text { Sectores fuera del bloque de } \\
\text { transferencias/servicios del } \\
\text { estado de bienestar }\end{array}$ & $\begin{array}{c}\text { Políticas de Servicios } \\
\text { Sociales }\end{array}$ \\
\hline $\begin{array}{l}\text { Funcionamiento excluyente de } \\
\text { mercados de vivienda con acción } \\
\text { pública débil }\end{array}$ & $\begin{array}{l}\text { Sectores sin acceso a la } \\
\text { vivienda } \\
\text { Colectivos espacialmente } \\
\text { segregados }\end{array}$ & $\begin{array}{c}\text { Politicas de vivienda } \\
\text { social } \\
\text { Políticas de } \\
\text { regeneración urbana }\end{array}$ \\
\hline
\end{tabular}

Fuente: Elaboración propia. 
RIS

REVISTA INTERNACIONAL DE SOCIOLOCIA

N 33, Septiembre-Diciembre, 2002

QUIM BRUGUÉ, RICARD GOMȦ y JOAN SUBIRATS

\section{EXCLUSIÓN SOCIAL. ALCANCE Y PERFILES}

La tabla 2 muestra, para el conjunto de estados de la UE, las cifras de desigualdad de rentas, de pobreza relativa sobre las medias nacionales y europea, y el porcentaje de ingresos salariales bajos sobre el salario medio nacional. Son tres tipos de indicadores con capacidad para ofrecer una primera imagen con regularidades consistentes. Se da una fuerte correlación positiva entre desigualdad, pobreza y salarios bajos. Aparecen dos excepciones: Irlanda, con un índice de Gini desproporcionadamente bajo en relación con su alta tasa de pobreza relativa; y Portugal, con una brecha salarial también por debajo de sus tasas de desigualdad y pobreza. En el resto de casos, además, la consistencia entre indicadores se da en el marco de un agrupamiento entre paises coherente con los regímenes de bienestar: los nórdicos presentan las menores tasas comparadas de desigualdad, pobreza e infrasalarios; los anglosajones y los del sur se sitúan en el extremo opuesto; con los estados continentales en valores intermedios.

Tabla 2.

Desigualdad, pobreza e infrasalarización en Europa.

\begin{tabular}{lcccc}
\hline & $\begin{array}{c}\text { Desigualdad } \\
\text { Índice de Gini }\end{array}$ & $\begin{array}{c}\text { Pobreza } \\
\text { Relativa (\%)* }\end{array}$ & $\begin{array}{c}\text { Pobreza relativa } \\
(\text { media UE) (\%) }\end{array}$ & $\begin{array}{c}\text { Salarios bajos } \\
(\%)^{* *}\end{array}$ \\
\hline Finlandia & 0,176 & 4,6 & 5,8 & 5,9 \\
Noruega & 0,213 & 5,0 & 5,1 & --- \\
Suecia & 0,242 & 5,5 & 5,9 & 5,2 \\
Dinamarca & 0,243 & 6,5 & 4,4 & 0,1 \\
Bélgica & 0,251 & 12,6 & 8,7 & 7,2 \\
Irlanda & 0,255 & 20,0 & 28,3 & 18,0 \\
Alemania & 0,280 & 10,9 & 7,6 & 13,3 \\
Holanda & 0,295 & 11,4 & 9,2 & 11,9 \\
Luxemburgo & 0,298 & 12,9 & 1,3 & --- \\
Francia & 0,303 & 13,1 & 10,5 & 13,3 \\
Italia & 0,348 & 17,9 & 23,8 & 12,5 \\
Grecia & 0,354 & 21,8 & 42,0 & --- \\
España & 0,354 & 19,1 & 31,7 & 19,0 \\
Gran Bretaña & 0,357 & 20,6 & 14,8 & 19,6 \\
Portugal & 0,473 & 26,8 & 47,5 & 12,0 \\
\hline
\end{tabular}

* Pobreza Relativa: población que vive con unos ingresos inferiores al $50 \%$ del ingreso medio.

** Salarios bajos: por debajo de $2 / 3$ del salario medio.

Fuente: Elaboración propia a partir de Eurostat. Panel de los hogares de la Unión Europea, 1998. 
La tabla 3 nos transporta hacia la realidad española. Una primera apreciación tiene que ver con la ubicación de España en el grupo de estados de la Unión Europea con índices más altos de pobreza, desigualdad e infrasalarización ${ }^{1}$ (Bazaga et $a l ., 2000)$. En el interior, las desigualdades entre CC.AA. aparecen también con fuerza. Las cinco comunidades de menor renta (Extemadura, Andalucía, Canarias, Castilla-La Mancha y Murcia) son también aquellas que presentan los índices más

Tabla 3.

Desigualdad, renta e intensidades de la pobreza en las CC.AA.

\begin{tabular}{|c|c|c|c|c|c|c|c|}
\hline & \multirow[b]{2}{*}{$\begin{array}{r}\text { Desigualdad } \\
\text { Indice Gini }\end{array}$} & \multirow[b]{2}{*}{$\begin{array}{l}\text { Renta } \\
\text { (Orden y } \\
\text { Nivel) }\end{array}$} & \multirow[b]{2}{*}{$\begin{array}{l}\text { Pobreza } \\
\text { Relativa }\end{array}$} & \multicolumn{4}{|c|}{$\begin{array}{l}\text { Distribución de intensidades sobre el } \\
\text { total de población en pobreza }\end{array}$} \\
\hline & & & & $\begin{array}{l}\text { Pobreza } \\
\text { Severa }\end{array}$ & $\begin{array}{c}\text { Pobreza } \\
\text { Grave }\end{array}$ & $\begin{array}{c}\text { Pobreza } \\
\text { Moderada }\end{array}$ & $\begin{array}{c}\text { Umbral } \\
\text { de } \\
\text { pobreza }\end{array}$ \\
\hline Andalucía & 0,324 & 16 (Baja) & 30,2 & 5,0 & 11,1 & 35,3 & 48,6 \\
\hline Aragón & 0,282 & 8 (Media) & 22,3 & 5,3 & 7,5 & 34,5 & 52,7 \\
\hline Asturias & 0,255 & 7 (Media) & 16,2 & 2,4 & 9,3 & 36,9 & 51,4 \\
\hline I.Baleares & 0,293 & 4 (Alta) & 18,6 & 4,2 & 14,3 & 26,6 & 54,9 \\
\hline Canarias & 0,319 & 15 (Baja) & 27,1 & 3,5 & 11,8 & 33,6 & 51,1 \\
\hline Cantabria & 0,301 & 9 (Media) & 17,7 & 4,9 & 6,7 & 28,9 & 58,6 \\
\hline Castilla-Mancha & 0,304 & 13 (Baja) & 30,7 & 2,7 & 5,9 & 42,6 & 48,8 \\
\hline Castilla- León & 0,285 & 10 (Media) & 25,5 & 2,9 & 9,1 & 39,2 & 48,7 \\
\hline Cataluña & 0,316 & 2 (Alta) & 16,1 & 2,0 & 13,9 & 31,6 & 52,5 \\
\hline Extremadura & 0,289 & 17 (Baja) & 45,6 & 4,9 & 11,3 & 45,0 & 38,8 \\
\hline Galicia & 0,299 & 12 (Baja) & 21,3 & 3,9 & 13,0 & 32,9 & 50,2 \\
\hline Madrid & 0,343 & 1 (Alta) & 11,1 & 5,1 & 8,9 & 35,8 & 50,2 \\
\hline Murcia & 0,362 & 14 (Baja) & 30,5 & 5,2 & 10,6 & 29,1 & 55,1 \\
\hline Navarra & 0,264 & 6 (Alta) & 11,0 & 1,6 & 4,7 & 36,8 & 56,9 \\
\hline P.Valenciano & 0,292 & 11 (Media) & 24,5 & 4,9 & 9,5 & 38,5 & 47,1 \\
\hline País Vasco & 0,301 & 5 (Alta) & 12,6 & 1,2 & 7,8 & 38,6 & 52,4 \\
\hline La Rioja & 0,303 & 3 (Alta) & 15,2 & 3,2 & 6,5 & 21,4 & 68,9 \\
\hline Total & 0,305 & & 22,1 & 4,0 & 10,5 & 35,9 & 49,6 \\
\hline
\end{tabular}

Fuente: Elaboración propia a partir de Equipo Edis (1998). Las condiciones de vida de la población pobre en España. Foessa, Madrid.

' El valor diferente del Índice de Gini para España entre la tabla 2 y 3 se explica por la diversidad de fuentes utilizadas. En la tabla 2, el Eurostat de la UE; en la tabla 3, la Encuesta de Presupuestos Familiares que incluye la distribución por CC.AA. de los datos de pobreza. 
RIS

REVISTA INTERNACIONAL DE SOCIOLOCIA

$\mathrm{N}^{\circ} 33$, Septiembre-Diciembre, 2002

QUIM BRUGUÉ, RICARD GOMÀ y JOAN SUBIRATS

elevados de pobreza relativa. Cuatro de ellas, además, se sitúan entre el grupo de seis con mayores tasas de desigualdad económica. Si se observa el peso que los núcleos duros de pobreza (la suma de los índices de pobreza severa y grave) ${ }^{2}$ tienen sobre el conjunto de ésta, la imagen anterior sale más reforzada. El peso de la pobreza de alta intensidad en las cinco CC.AA. más pobres llega a una media del 14,25\% (15,90\% en las cuatro de mayor pobreza), por el contrario, en las cinco CC.AA. de renta más elevada (Madrid, Cataluña, Baleares, País Vasco y Navarra), esa cifra se situa en el $11,5 \%$. Cabe destacar, finalmente, que los menores índices de desigualdad no se dan entre las comunidades más ricas, sinó entre las que ocupan lugares intermedios (Aragón, Asturias, Castilla y León, País Valenciano y Galicia). Lo que muestra la tendencia hacia patrones de crecimiento sólidos pero con fuertes desigualdades internas, es decir, poco inclusivos y cohesionados. Navarra es quizás la excepción remarcable a este patrón, ya que se sitúa en el grupo de renta alta, pero con un índice de desigualdad entre los más bajos. Su tradición en planes de lucha contra la pobreza y la exclusión puede haber sido un factor explicativo importante.

Hasta ahora, hemos ido aportando un conjunto de indicadores y reflexiones sobre el alcance y la distribución de la pobreza. Ésta, caracterizada por la carencia relativa de recursos económicos, es un eje básico para el estudio de la exclusión. Sin embargo, tal como sosteníamos antes, la exclusión social es multidimensional; así pues, la dimensión pobreza, cuando desemboca en una realidad compleja de marginación, se presenta en contacto con otras dimensiones de la precariedad personal. Antes de entrar en la matriz de la exclusión, cabe señalar las fuertes relaciones que se dan en España entre las situaciones de pobreza y los riesgos y precariedades sufridas en los mercados de trabajo y de vivienda:

- Desde una óptica comparada, las relaciones entre pobreza y paro son más complejas de lo que parece. En los estados sociales más avanzados, el desempleo dificilmente supone pobreza y exclusión. Las políticas públicas ofecen redes de asistencia de base individual (no familiar) y palancas de reinserción que lo evitan (Kautto et al., 2001). En otros casos, en EEUU por ejemplo, no ya el paro, sino el mismo trabajo ha dejado de ser una garantía contra la exclusión. La infrasalarización y los macjobs han avanzado tanto que la creación ingente de ocupación no ha supuesto frenar las tendencias hacia la dualización y la pobreza excluyente. España se sitúa a medio camino. Un $11,7 \%$ de las familias con los dos adultos ocupados se hallan en situación de pobreza, hecho que empieza a mostrar también

\footnotetext{
${ }^{2}$ Adoptamos la clasificación de la pobreza en cuatro intensidades según niveles de ingresos personales o del hogar, calculados sobre la renta per cápita nacional: severa (menos del $15 \%$ ), grave (entre el $16 \%$ y el $25 \%$ ), moderada (entre el $26 \%$ y el $35 \%$ ) y umbral de la pobreza (entre el $36 \%$ y el $50 \%)$.
} 
aquí la extensión del empleo precarizado. Sin embargo, la tasa de pobreza no aumenta en las familias con todos los adultos inactivos, generalmente jubilados, lo que viene a mostrar el enorme impacto social del sistema de pensiones. La cifra más alamarte se da entre las familias con todos los adultos desempleados; en este caso, la pobreza llega al $59,7 \%$ de las familias.

- En cuanto a las relaciones entre niveles de pobreza y variables de vivienda y hábitat, puede observarse que la población en situación de pobreza intensa (severa y grave) en España vive de forma mayoritaria en barrios degradados, habita en viviendas con problemas graves de deterioro y sufre hacinamiento, entendido éste en el doble sentido de disponer de menos de $10 \mathrm{~m}^{2}$ por persona (por debajo de un tercio de la media estatal) y de menos de un dormitorio para cada dos personas. Además, en el $27 \%$ de los casos de pobreza intensa, las viviendas carecen de equipamiento básico (agua corriente, luz eléctrica, váter particular y agua caliente). Asimismo, la máxima concentración de degradación urbana, infravivienda y hacinamiento la sufre aquella población que, además de presentar pobreza, tiene un origen étnico o nacional minoritario (población gitana o inmigrantes extracomunitarios). Hecho que aporta un dato enriquecedor del panorama poliédrico de la exclusión en España.

- Ahondando en la dimensión territorial y urbana de la exclusión social en España, la tabla 4 muestra la existencia de 330 barrios, en ciudades de más de 50.000 habitantes de las siete autonomías españolas con mayor capacidad de autogobierno, en los que se acumulan unas tasas de desempleo, analfabetismo

Tabla 4.

Exclusión social urbana. Barrios multidegradados. Aspectos socio-habitacionales.

\begin{tabular}{lcrrccc}
\hline & $\begin{array}{c}\text { *Barrios en } \\
\text { degradacion }\end{array}$ & $\begin{array}{c}\text { Total } \\
\text { Población }\end{array}$ & $\begin{array}{c}(\%) \\
\text { Población }\end{array}$ & $\begin{array}{c}\text { (\%) } \\
\text { Desempleo }\end{array}$ & $\begin{array}{c}\text { (\%) población ** Vivienda } \\
\text { sin estudios }\end{array}$ & $\begin{array}{l}\text { infraequipada } \\
\text { indalucía }\end{array}$ \\
\hline And & 160 & 1.296 .708 & 40,7 & 34,7 & 28,4 & 2,6 \\
Canarias & 38 & 305.924 & 41,2 & 33,6 & 21,1 & 1,3 \\
Cataluña & 41 & 313.636 & 8,8 & 23,7 & 22,6 & 1,8 \\
Galicia & 15 & 94.401 & 9,9 & 26,4 & 17,9 & 1,6 \\
Navarro & 2 & 18.918 & 10,5 & 21,0 & 12,6 & 0,8 \\
P. Valenciano & 24 & 199.131 & 12,3 & 29,9 & 27,1 & 1,2 \\
P. Vasco & 12 & 94.236 & 8,3 & 34,9 & 14,1 & 0,5 \\
\hline
\end{tabular}

* Barrios de ciudades de más de 50.000 habitantes con medias de desempleo, analfabetismo e infravivienda superiores en un $50 \%$ a la media estatal.

** Viviendas sin agua, WC, baño ni ducha.

Fuente: La desigualdad urbana en España (2000) (p.43-65) 
e infravivienda superiores en un $50 \%$ a la media estatal. Son, por tanto, barrios sujetos a procesos de multidegradación que expresan la existencia tanto de espacios de exclusión como de fuertes desigualdades urbanas en las ciudades españolas. Estos barrios congregan al $18,81 \%$ de la población urbana, un total de 2.322.954 personas, entre las siete comunidades. La visión territorializada de estos datos arroja un panorama complejo. Algunas comunidades, como Andalucía $\mathrm{y}$ algo menos Canarias, tienden a situarse siempre en la franja alta de indicadores negativos. Otras, como el País Vasco y Navarra, se sitúan normalmente en las cotas de menor degradación urbana. Se dan, sin embargo, muchas situaciones intermedias y matizadas. Mientras en Andalucía y Canarias la población en barrios desfavorecidos supera el $40 \%$, en Cataluña, Galicia y el País Vasco no llega al $10 \%$. Mientras en Andalucía la vivienda sin ningún tipo de equipamiento básico representa el 2,6\% de todas las viviendas en barrios degradados, en el País Vasco y Navarra no llega al $0,8 \%$. Finalmente los diferenciales de desempleo y analfabetismo son tambien importantes.

Más allá de las cifras de pobreza y de desigualdad, y más allá de la puesta en relación de éstas con las esferas del trabajo y de la vivienda, es posible proponer una primera matriz de colectivos altamente vulnerables a procesos de exclusión social (tabla 5). La matriz propuesta se construye a partir de cruzar un conjunto de factores de exclusión que operan en varias esferas o ámbitos (laboral, formativo, sociosanitario, urbano-territorial, familiar-relacional, político y penal), con otro

Tabla 5.

Ambitos, circunstancias y colectivos vulnerables a la exclusión social.

\begin{tabular}{|c|c|c|c|c|c|c|c|}
\hline \multicolumn{8}{|c|}{ Ámbitos donde pueden operar factores de exclusión } \\
\hline CIE* & $\begin{array}{l}\text { Exclusión } \\
\text { económica }\end{array}$ & $\begin{array}{l}\text { Exclusión } \\
\text { Laboral }\end{array}$ & $\begin{array}{l}\text { Exclusión } \\
\text { Educativa }\end{array}$ & $\begin{array}{l}\text { Exclusión } \\
\text { Socio- } \\
\text { sanitaria }\end{array}$ & $\begin{array}{l}\text { Exclusión } \\
\text { Urbana- } \\
\text { Territorial }\end{array}$ & $\begin{array}{l}\text { Exclusión } \\
\text { Familiar- } \\
\text { Relacional }\end{array}$ & $\begin{array}{l}\text { Exclusión } \\
\text { Política/de } \\
\text { ciudadanía }\end{array}$ \\
\hline Sexo & \multirow{4}{*}{\multicolumn{7}{|c|}{$\begin{array}{l}\text { COLECTIVOS DE POBLACIÓN ALTAMENTE } \\
\text { VULNERABLES A PROCESOS DE EXCLUSIÓN SOCIAL }\end{array}$}} \\
\hline Edad & & & & & & & \\
\hline $\begin{array}{l}\text { Etnia } \\
\text { (Origen) }\end{array}$ & & & & & & & \\
\hline $\begin{array}{l}\text { Clase } \\
\text { Social }\end{array}$ & & & & & & & \\
\hline
\end{tabular}

* Circunstancias Intensificadoras de la Exclusión Social.

Fuente: Elaboración propia. 
conjunto de elementos estructurales que operan como circunstancias intensificadoras del riesgo de exclusión (sexo, edad, etnia-origen y clase social). Por poner sólo algunos ejemplos: la precariedad laboral, el analfabetismo digital, una discapacidad psíquica, la infravivienda, la desestructuración familiar, la insuficiencia de la protección social, o el paso por la cárcel (factores) pueden operar como potentes fuentes de generación de exclusión. Estas fuentes incidirán con más fuerza en grupos de alta vulnerabilidad estructural: mujeres, jóvenes, personas mayores, inmigrantes, o clases de rentas bajas (circunstancias intensificadoras).

\section{LAS POLÍTICAS PÚBLICAS FRENTE A LA EXCLUSIÓN SOCIAL}

La exclusión social puede enfrentarse desde diferentes esferas de la sociedad y por medio de diferentes tipos de estrategias. El ámbito familiar puede convertirse en un espacio central proveedor de cuidados asistenciales, paliativos de situaciones intensivas de exclusión. El tejido comunitario puede ofrecer redes de apoyo que permitan mantener a personas y colectivos vulnerables relativamente al margen de "escaladas de exclusión". Desde el universo asociativo pueden incluso impulsarse mecanismos de desarrollo humano y de inserción de grupos de alto riesgo social o con fuertes dependencias. Siendo todo ello muy importante, en sociedades complejas como la nuestra los resortes clave de lucha contra la exclusión deben ubicarse en la esfera pública. Las políticas sociales, los programas y los servicios impulsados desde múltiples niveles territoriales de gobierno se convierten en las piezas fundamentales de un proyecto de sociedad cohesionada. Ahora bien, las políticas sociales contra la exclusión deben abandonar cualquier pretensión monopolista, profesionalista $o$ centralizadora. Su papel como palancas hacia el desarrollo social inclusivo será directamente proporcional a su capacidad de tejer sólidas redes de interacción con todo tipo de agentes comunitarios y asociativos, en el marco de sólidos procesos de deliberación sobre modelos sociales y bien apegadas al territorio.

Sobre estas bases, ofrecemos una breve conceptualización de las políticas sociales; situamos, en plena reestructuración del estado de bienestar, la emergencia de una dimensión anti-exclusión en las agendas de la UE y de sus estados; y llegamos a la realidad de España, aportando algunas evidencias y claves interpretativas sobre las políticas contra la marginación hasta hoy ensayadas.

\section{Políticas sociales y Estados de bienestar en transición}

Las acciones públicas contra la exclusión emergen como componentes de los modelos de bienestar en proceso de reestructuración. El Estado de bienestar es un espacio institucional público donde, por medio de un abanico de políticas sociales, se dirimen intereses y se resuelven necesidades colectivas. En sentido estricto, el campo de las políticas sociales se extiende, por un lado, a las intervenciones 
públicas sobre el plano laboral, es decir, sobre las pautas de inserción y exclusión de las personas en los mercados de trabajo; y, por otro lado, sobre el conflicto distributivo, es decir, sobre las tensiones por la asignación de valores, recursos y oportunidades entre grupos sociales. Cabe destacar que las políticas sociales no se agotan en la interacción Estado-mercado, ni su impacto se reduce a la mera corrección de desigualdades materiales:

- En primer lugar, el mercado no es el único espacio generador de desigualdades, como no es tampoco la única esfera social que está más allá de los poderes públicos. El Estado de bienestar desempeña, de hecho, múltiples papeles en el espacio complejo formado por las esferas pública, mercantil, familiar y asociativa (Adelantado, 2000). Las políticas sociales pueden desmercantilizar ciertos procesos, como pueden también desplazar al ámbito del Estado actividades previamente realizadas por las familias o el tejido asociativo. $\mathrm{O}$, en sentido inverso, el Estado de bienestar puede operar como factor de remercantilización, pero también de privatización familiarista o comunitaria de funciones de bienestar anteriormente absorvidas por la esfera pública.

- En segundo lugar, el tipo de impacto de las políticas sociales no puede darse por establecido. Los Estados de bienestar, por medio de su oferta de regulaciones y programas, operan como potentes factores de estructuración social: articulan y desarticulan, alteran, intensifican, erosionan, construyen o erradican fracturas y escisiones económicas, generacionales, étnicas o de género. Dicho de otro modo, su impacto es mucho más complejo y multidireccional de lo que puede parecer a simple vista.

En síntesis, las políticas de bienestar se conforman como espacios de gestión colectiva de los múltiples ejes de desigualdad - de clase, de ciudadanía, de género, etc.- que surcan las múltiples esferas - pública, mercantil, asociativa, familiar - que presentan las sociedades avanzadas de principios del siglo XXI.

Hasta principios de los años ochenta, los paises capitalistas avanzados presentan estructuras sociales homogéneas cruzadas por una lógica clasista de estratificación. Ello había comportado la consolidación histórica de un patrón de necesidades sociales uniformes, concentradas en la clase trabajadora y derivadas de la incapacidad de acceso a bienes básicos, en función de rentas salariales insuficientes o de salidas coyunturales del mercado laboral. A esta configuración de necesidades, el modelo clásico de bienestar responde con "una política social como política de clase", reflejada en una oferta centralizada-estandarizada de servicios y transferencias, articulada en torno a sistemas nacionales de salud y a mecanismos de seguro social (Baldwin, 1993).

A principios de los años 90 - cuando los factores antes analizados ya habían generado la nueva polarización inclusión/exclusión superpuesta al eje clásico de desigualdad vertical - ninguno de los regímenes de bienestar europeos se encuentra bien equipado, desde la perspectiva de su instrumental de acción, para 
enfrentar el problema de la exclusión social. A lo largo de estos últimos diez años ha habido avances notables, aunque desiguales. En todo caso, podemos afirmar que los Estados de bienestar han hallado en la exclusión uno de los yacimientos más importante de nuevas políticas sociales (Cuadro 1).

Cuadro 1.

Viejas y nuevas lógicas de desigualdad. Nuevos yacimientos de políticas.

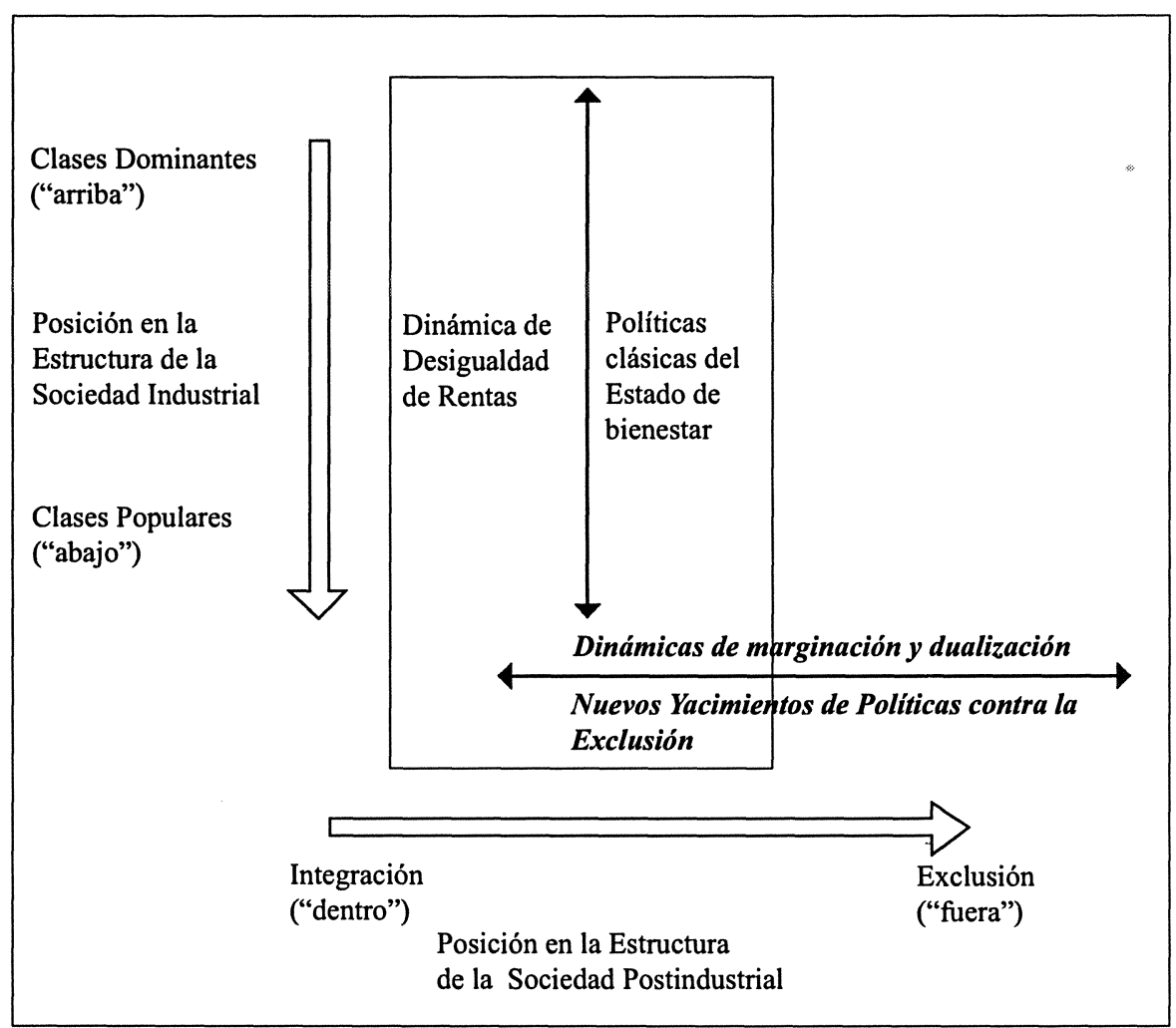

Fuente: Elaboración propia.

\section{La dimensión anti-exclusión en los regímenes de bienestar europeos}

Más allá del núcleo clásico de la protección social, todos los paises de la UE han puesto en pie ya nuevos regímenes contra la exclusión: políticas contra el paro juvenil y de larga duración, sistemas de servicios sociales y de transferencias asistenciales y programas de vivienda social y regeneración urbana. 
RIS

REVISTA INTERNACIONAL DE SOCIOLOCIA

№ 33, Septiembre-Diciembre, 2002

QUIM BRUGUÉ, RICARD GOMÀ y JOAN SUBIRATS

\section{Las politicas contra la exclusión del mercado de trabajo}

La tabla 6 muestra algunos datos significativos, en perspectiva comparada, en torno a la exclusión y la precariedad laboral, al gasto en políticas activas de inserción y a las tasas de cobertura e intensidad protectora de las políticas pasivas. En un extremo, los países nórdicos presentan los índices más bajos de desempleo de larga duración, con las políticas de inserción laboral más potentes y con las tasas combinadas más altas de protección y sustitución de ingresos de la población excluida del mercado de trabajo. En el otro extremo, los países del sur de Europa presentan los índices de exclusión y precariedad más elevados, junto al menor esfuerzo fiscal en programas de inserción y la menor tasa de cobertura del desempleo. Cabe destacar también el incremento de la tasa de temporalidad juvenil en todos los casos, aunque la interpretación de ésta en clave de precarización no debe hacerse de forma automática: en los modelos nórdico y continental conlleva un nivel de derechos laborales claramente por encima de los modelos anglosajón y latino. Finalmente, la caida de la intensidad protectora del seguro de desempleo es especialmente marcada en los casos continental y anglosajón, lo que tiende a generar bolsas de excluidos laborales de larga duración, débilmente cubiertos por subsidios asistenciales. Subsidios con poca o nula capacidad de revertir situaciones de pobreza, a no ser que se conecten a programas de reinserción activa; programas que, como puede verse, están lejos de responder a las necesidades en el arco latino-mediterráneo.

Tabla 6.

Las politicas contra la exclusión. Aspectos conectados al empleo.

\begin{tabular}{|c|c|c|c|c|c|c|c|}
\hline & \multirow{2}{*}{$\begin{array}{c}\begin{array}{c}\text { Tasa de } \\
\text { paro de } \\
\text { larga } \\
\text { duración }\end{array} \\
1998\end{array}$} & \multicolumn{2}{|c|}{$\begin{array}{c}\text { Tasa de } \\
\text { Temporalidad } \\
\text { Juvenil } \\
\end{array}$} & \multicolumn{2}{|c|}{$\begin{array}{l}\text { Gasto Público } \\
\text { en Políticas } \\
\text { activas (\% PIB) }\end{array}$} & \multirow{2}{*}{$\begin{array}{c}\begin{array}{c}\text { Tasa de } \\
\text { Cobertura } \\
\text { del paro }\end{array} \\
1998\end{array}$} & \multirow{2}{*}{$\begin{array}{c}\begin{array}{c}\text { Tasa de } \\
\text { Sustitución } \\
\text { de ingresos } \\
\left(2^{\circ} \text { año }\right)\end{array} \\
1998\end{array}$} \\
\hline & & 1981 & 1998 & 1981 & 1998 & & \\
\hline EB Nórdicos & 3,1 & 37,3 & 39,5 & 2,2 & 2,1 & 79,1 & 69,5 \\
\hline$E B$ Continentales & 3,8 & 21,3 & 36,0 & 0,9 & 1,0 & 56,4 & 48,4 \\
\hline EB Anglosajones & 5,6 & 12,9 & 16,5 & 0,9 & 1,0 & 57,7 & 26,7 \\
\hline EB Latino-Med & 8,1 & 29,0 & 40,2 & 0,5 & 0,6 & 20,3 & 54,5 \\
\hline
\end{tabular}

Fuente: OCDE, Social expenditure database, 1999. 
Las políticas contra la pobreza: rentas asistenciales y vivienda social

Si trasladamos el análisis a las políticas que, más allá del desempleo, abren el abanico de las exclusiones (servicios sociales y transferencias asistenciales) observamos que el diseño de estos programas anti-exclusión varía sobre 3 ejes cualitativos:

- Su grado de normativización, es decir, hasta qué punto las políticas se apoyan en procesos de constitucionalización de derechos y no dependen en exclusiva de voluntades políticas puntuales y reversibles. Las diferencias son aquí amplias entre bloques de paises: la expresión normativa del MTA (Modelo de Transferencias Asistenciales) en los Estados continentales y mediterráneos, es por lo general, todavía baja.

- El tipo de transferencias predominantes. En los Estados de bienestar anglosajones se da la máxima complejidad de tipos: se conjugan, a un nivel similar, subsisdios no categorizados y no finalistas (rentas mínimas), con otros no finalistas pero categorizados (madres solas, personas con disminuciones...) y con los finalistas no categorizados (el housing benefit británico). Los nórdicos descansan mucho más sobre las rentas mínimas de inserción, mientras los continentales y los paises del sur siguen priorizando las transferencias categorizadas, aunque con avances relevantes de las rentas mínimas en Francia y España (García Romero, 1999).

- El nivel territorial predominante. A excepción del régimen de bienestar anglosajón, que sigue centralizando el diseño del MTA, los procesos de formulación multinivel de las políticas anti-exclusión predominan en todos los paises.

Desde una perspectiva más cuantificable, se observa cómo todos los Estados de la UE, sin excepción, han incrementado tanto las tasas de cobertura como el gasto relativo en el sistema asistencial. Finalmente, la tabla 8 incorpora datos sobre la evolución de las políticas de vivienda social. En este campo se observa un claro estancamiento generalizado, incluso a la baja, que coexiste con desigualdades enormes de política pública: en los paises del sur sólo un 3,6\% de las viviendas forman parte de la oferta pública en alquiler, en contraposición al $18 \%$ de media de los otros tres bloques de estados (Kleinman et al., 1998).

\section{LA DIMENSIÓN ANTI-EXCLUSIÓN EN LA POLÍTICA SOCIAL DE LA UE}

Más allá de lo acontecido en el ámbito de los Estados, uno de los hechos más relevantes en el panorama europeo ha sido la asunción de responsabilidades de acción contra la exclusión por parte de la UE (Kleinman, 2002). Las iniciativas contra la exclusión se han caracterizado por cuatro notas:

a) El desarrollo en un amplio abanico de programas de acción, pero sin ninguna expresión relevante en la esfera legislativa (directivas comunitarias). 


\section{R I S}

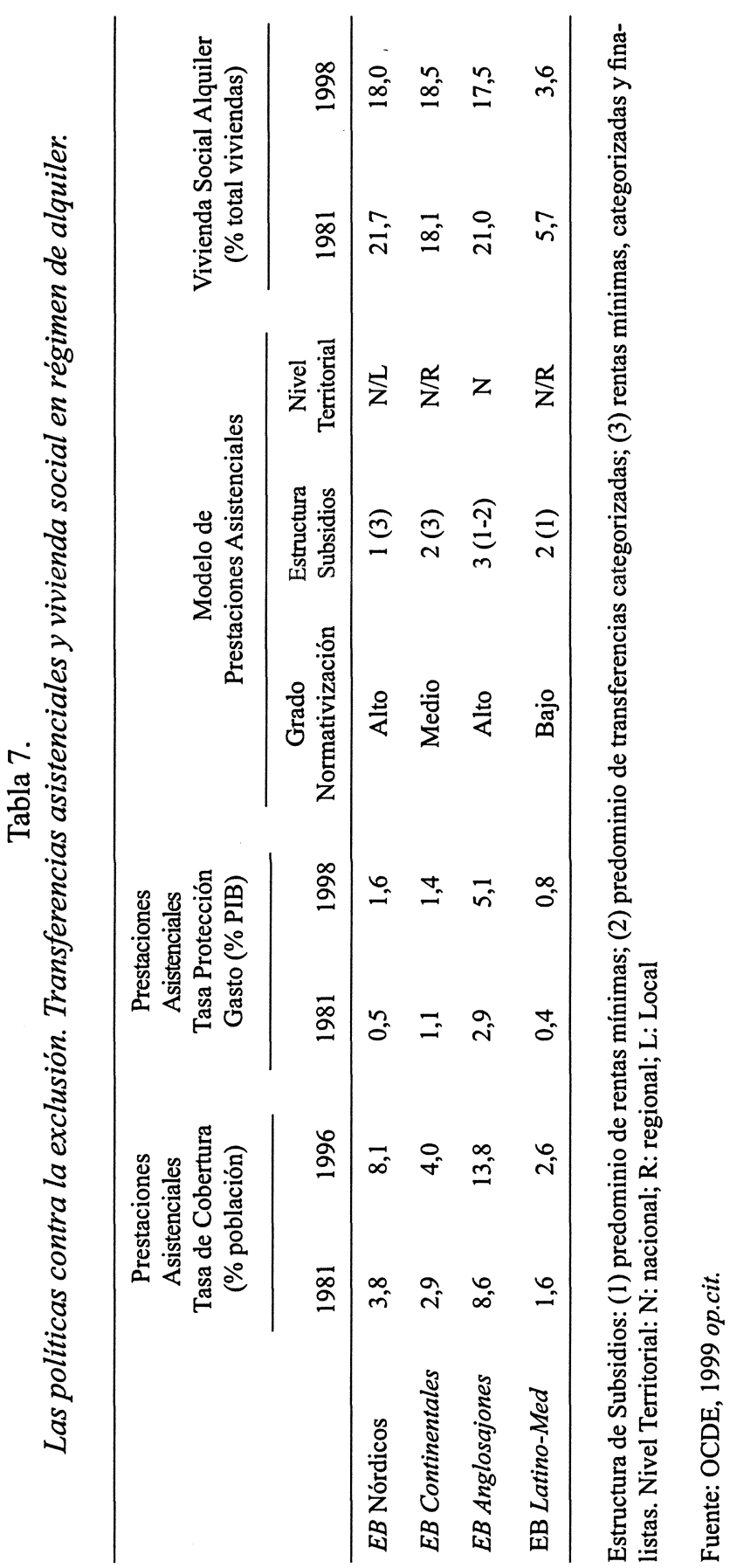


b) El debate en torno al principio de subsidiariedad, ¿hasta qué punto debe la UE intervenir en un terreno - la exclusión social- donde la proximidad es un factor clave de eficacia?

c) La adopción de la escasez de rentas (la pobreza en sentido estricto) como criterio principal de acción, apoyado por tres criterios adicionales: étnicos, generacionales y sociosanitarios.

d) El desplazamiento progresivo del problema de la exclusión laboral hacia la agenda social de la política de cohesión.

\section{Las politicas europeas contra la exclusión del mercado de trabajo}

La acción contra la exclusión a escala comunitaria se ha vehiculado, de manera principal, por medio de la política de cohesión. Entre 1994 y 1999 , la estrategia de cohesión implica un gasto comunitario cercano a los 150.000 millones de euros. Volumen que representa en torno al $1 \%$ del gasto público agregado de los Estados (hacia el 0,46\% del PIB de la Unión) (Hooghe, 1996). Los parámetros de la cohesión para la fase 2000-2006 pueden sintetizarse en 5 puntos:

- Se establece una cifra de gasto estructural de 213.000 millones de euros, lo que supone una caida de 3 puntos (del $36 \%$ al 33\%) en la participación de la cohesión sobre gasto total de la UE. Gasto que, se situa alrededor del $1,1 \%$ del PIB de la Unión.

- Se diseña una reducción y simplificación de objetivos, que quedan ahora en tres: dos objetivos de política regional (el apoyo a las regiones con rentas inferiores al $75 \%$ de la media de la UE y el apoyo a las regiones en proceso de reconversión estructural: industrial, urbana, rural o pesquera) y un objetivo de política social (formación y promoción del empleo, especialmente entre los grupos más vulnerables a la exclusión).

- La dimensiones federal y social de la cohesión retroceden, las iniciativas comunitarias representan sólo el $6 \%$ del gasto (frente al $10 \%$ del periodo anterior); a la dimensión social (objetivo 3 ) se le asigna sólo el 14\% de los recursos (frente al $33 \%$ de 1994). Sin embargo, a este $14 \%$ cabe añadir todos los recursos estatales que financiarán los PNAE, en el marco de la Estrategia Europea de Empleo.

- Se diseña una reducción y simplificación de las iniciativas comunitarias. Por una parte, las de política regional pasan de diez a tres (INTERREG, URBAN y LEADER). Por otra parte, las de política social pasan de 5 a 1 (el programa EQUAL). Cabe destacar, como aspecto positivo el hecho que los tres programas regionales, sobre todo el URBAN, presentan una fuerte vocación de concentración de recursos en áreas socialmente deprimidas y hacia la inversión en infraestructuras sociales, conectadas a las necesidades de los residentes.

- Se diseña una última simplificación. Cada IC se conecta a un solo fondo estructural. Así el programa EQUAL será financiado exclusivamente a cargo del 
RIS

Fondo Social Europeo (el FEDER financiará los programa URBAN). El FSE podrá destinar también fondos a la financiación de la EEE, incluso por la vía del EQUAL, hecho que completa la fuerte vinculación entre el Proceso de Luxemburgo y la reforma de la cohesión.

\section{Políticas europeas contra la pobreza y otras vertientes de la exclusión}

En el terreno de la pobreza, la UE ha llevado a cabo tres Programas-Marco de Acción Comunitaria, entre 1975 y 1994, con un presupuesto global cercano a los 15.000 millones de pesetas y unos 130 proyectos concretos de base territorial. El programa Pobreza-III (1989-1994) supuso la realización de 41 proyectos piloto contra la exclusión de gran carga innovadora. El activismo comunitario de principios de los 90, en el terreno de la pobreza, contrasta con un hecho clave: la cancelación brusca y radical de esta línea de actuación tras 1994, con la sistemática denegación de aprobación por el Consejo del IV Programa de Acción Comunitaria contra la exclusión (1994-1999). Sin embargo, la Agenda de Política Social 20002005 abre una perspectiva de desbloqueo. En ella se afirma el compromiso de aprobar un nuevo Programa de Acción de la Unión para combatir la exclusión y la discriminación. El Programa se encuentra actualmente en marcha, su elaboración se rige por el principio de coordinación abierta, es decir, directrices europeas y programas nacionales van a ser evaluados a escala de la Unión.

\section{EXCLUSIÓN Y POLÍTICAS PÚBLICAS EN ESPAÑA}

En España, las políticas contra la exclusión presentan una triple complejidad. Por una parte, se insertan de lleno en la lógica del gobierno multinivel; todas las esferas territoriales de gobierno tienen algún tipo de presencia institucional en la lucha contra la exclusión. Y, más relevante aún, crece el convencimiento sobre la interdependencia entre dichas esferas, a la hora de afrontar la inmensa mayoría de problemáticas. Por otra parte, la política social contra la exclusión se presenta fragmentada en un amplísimo abanico de programas, servicios e instrumentos de acción pública. Muchos de ellos específicos, otros muchos formando parte de la transversal anti-exclusión presente en múltiples campos de actuación (educación, sanidad, ocupación, vivienda...). Finalmente, la red de acción contra la exclusión se encuentra poblada por actores de todo tipo: públicos, comunitarios, asociativos y hasta mercantiles. También entre ellos van en aumento las percepciones de interdependencia, cuando no de claras sinergias derivadas de prácticas de concertación y acuerdo horizontal.

En el marco de este complejo panorama, aportamos algunas notas de síntesis en relación con un componente institucional clave en la estrategia contra la exclusión: el sistema público de base autonómica de servicios sociales y rentas mínimas. 
Tabla 8.

Politicas contra la exclusión social de la UE (excepto iniciativas a cargo del Fondo Social Europeo).

\begin{tabular}{|c|c|c|}
\hline ÁMBITO & $\begin{array}{l}\text { RÉGIMEN REGULATIVO } \\
\text { EUROPEO }\end{array}$ & $\begin{array}{l}\text { PROGRAMAS DE ACCIÓN Y } \\
\text { REDES EUROPEAS }\end{array}$ \\
\hline POBREZA & $\begin{array}{l}\text { - Resolución sobre combate contra } \\
\text { la exclusión (1989) } \\
\text { - Recomendación suficiencia de } \\
\text { recursos en programas de } \\
\text { asistencia (1992) } \\
\end{array}$ & $\begin{array}{l}\text { - POBREZA I (1974-1980) } \\
\text { - POBREZA II (1985-1989) } \\
\text { - POBREZA III (1989-1994) } \\
\text { - PA contra la Exclusión (2000-2006) }\end{array}$ \\
\hline $\begin{array}{l}\text { EXCLUSIÓN } \\
\text { LABORAL } \\
\end{array}$ & & $\begin{array}{l}\text { - ERGO I (1989-1992) } \\
\text { - ERGO II (1993-1996) }\end{array}$ \\
\hline INMIGRACIÓN & $\begin{array}{l}\text { - Directiva educación hijos/as de } \\
\text { inmigrantes (1977) } \\
\text { - Resolución contra el racismo } \\
(1986-1990) \\
\text { - Comunicación sobre inmigración } \\
\text { (1991-1994) } \\
\text { - Informe educación de hijos/as de } \\
\text { inmigrantes (1994) } \\
\text { - Comunicación sobre racismo, } \\
\text { xenofobia y antisemitismo (1995) } \\
\text { - Directiva de igualdad y no discri- } \\
\text { minación en función del orígen } \\
\text { étnico (2000) } \\
\text { - Directiva de igualdad y no } \\
\text { discriminación étnica en la esfera } \\
\text { laboral (2000) }\end{array}$ & $\begin{array}{l}\text { - RIMET (desde 1991) } \\
\text { - ELAINE (desde 1993) } \\
\text { - Programa comunitario contra el } \\
\text { racismo } \\
\text { - Año contra el racismo (1997) } \\
\text { - Agencia Europea contra el } \\
\text { racismo y la xenofobia de Viena } \\
\text { - Programa de Acción contra la } \\
\text { discriminación (2001-2006) }\end{array}$ \\
\hline SOCIOSANITARIO & $\begin{array}{l}\text { - Resolución empleo personas con } \\
\text { minusvalías (1986) } \\
\text { - Resolución integración escolar } \\
\text { (1990) } \\
\text { - Comunicación igualdad de oportu- } \\
\text { nidades (1993) } \\
\text { - Informe acceso al transporte (1996) }\end{array}$ & $\begin{array}{l}\text { - HELIOS I (1988-1991) } \\
\text { - HELIOS II (1993-1996) } \\
\text { - HELIOS III (1996-2000) } \\
\text { - Sistema HANDYNET } \\
\text { - TIDE (1991-1995) } \\
\text { - TELEMTICS (1996-2000) } \\
\text { - Programa contra las drogas (1996-2000) } \\
\text { - Programa prevención SIDA(1996-2000) }\end{array}$ \\
\hline $\begin{array}{l}\text { PERSONAS } \\
\text { MAYORES }\end{array}$ & $\begin{array}{l}\text { - Recomendación sobre política } \\
\text { comunitaria hacia las personas } \\
\text { jubiladas (1982) } \\
\text { - Resolución tarjeta cultural y trans- } \\
\text { portes para mayores de } 60 \text { años } \\
\text { (1989) } \\
\text { - Resolución sobre programas de } \\
\text { jubilación flexible (1993) }\end{array}$ & $\begin{array}{l}\text { - Programa comunitario hacia las } \\
\text { personas mayores (1991-1996) } \\
\text { - TIDE (1991-1995) } \\
\text { - TELEMATICS (1996-2000) }\end{array}$ \\
\hline
\end{tabular}

Fuente: Elaboración propia. 
RIS

\section{Las Redes de Servicios Sociales}

Los servicios sociales son una de las piezas más vulnerables en la arquitectura institucional del Estado de bienestar español. Por un lado, su normativización es débil, por cuanto no fueron incorporados, en el bloque constitucional-estatutario, al campo de los derechos sociales de ciudadanía. Por otro lado, su demanda está poco articulada, y no existe una opinión pública de apoyo claro a la extensión de los servicios: muchos barrios se han movilizado en demanda o defensa de escuelas y hospitales; ¿cuántos lo han hecho en demanda de, por ejemplo, programas de salud mental, centros de día, o servicios de atención domicilaria?.

Todo ello ha ido apartando a los servicios sociales en España de una concepción universalista, de tipo socialdemócrata; por el contrario, los ha situado en tasas de cobertura e intensidad mucho más selectivas y débiles (Adelantado, Jiménez, 2002). En ese contexto - y esta puede ser la otra cara de la moneda - los servicios sociales han tendido a orientar y focalizar su trabajo hacia los grupos de riesgo: personas y sectores vulnerables a la marginación, o bien en situaciones abiertas de precariedad social. Así pues, la conexión entre servicios sociales y exclusión se ha ido haciendo más y más fuerte.

Ante la enorme complejidad de la oferta de servicios sociales en el terreno de la exclusión, y la imposibilidad de su análisis en un espacio breve, optamos por una vía de aproximación alternativa. A partir de datos de encuesta ya disponibles, reflexionamos en torno a dos aspectos clave: las tasas de acceso a las diferentes redes de servicios y los grados de eficacia de éstos a partir de percepciones subjetivas de resolución o no de problemas. Para los dos aspectos, la población de referencia es aquella que se sitúa por debajo del umbral de pobreza relativa.

- En relación al acceso de la población pobre a los servicios sociales, la tabla 9 pone en relación las tasas de acceso global al sistema de servicios sociales con el nivel de utilización relativa de las redes públicas y asociativas.

Observamos cómo en diez CC.AA., las tasas de acceso se sitúan por encima del $50 \%$ de la población pobre, mientras que en las siete restantes no se llega a esa misma cifra. Las CC.AA. con servicios sociales más inclusivos en el terreno de la pobreza son también las que presentan un uso mayor de las redes públicas y de los equipos de atención primaria. Por el contrario, entre las CC.AA. con menor inclusividad (por debajo de un $50 \%$ de acceso de la población pobre a los servicios) tienden a predominar las redes asociativas y la atención especializada.

- La percepción de la población pobre que accede a los servicios sociales acerca de la eficacia de éstos en la resolución de sus problemas no presenta grandes disparidades entre Comunidades Autónomas. Algo significativo aflora cuando los niveles de acceso y los de satisfacción subjetiva se ponen en relación no ya con su distribución territorial por CC.AA., sino con los distintos grados de intensidad de pobreza de la población usuaria. Tal como se muestra en la tabla 11, el recrudecimiento de la pobreza implica un uso mayor de las redes de Cáritas y 
Tabla 9.

Servicios Sociales y Pobreza: acceso y tipos de redes.

\begin{tabular}{lcc}
\hline & $\begin{array}{c}\text { USO MAYORITARIO DE LAS } \\
\text { REDES PUBLICAS } \\
\text { (Municipales y autonómicas) }\end{array}$ & $\begin{array}{c}\text { USO MAYORITARIO DE LAS } \\
\text { REDES ASOCIATIVAS } \\
\text { (Cáritas y Cruz Roja) }\end{array}$ \\
\hline $\begin{array}{l}\text { TASA DE ACCESO } \\
\text { ALTA } \\
\text { + 50\% población pobre) }\end{array}$ & $\begin{array}{c}\text { Aragón Navarra } \\
\text { Asturias País Valenciano } \\
\text { Canarias País Vasco } \\
\text { Cataluña La Rioja }\end{array}$ & $\begin{array}{c}\text { Andalucía } \\
\text { Cantabria }\end{array}$ \\
$\begin{array}{l}\text { TASA DE ACCESO } \\
\text { BAJA } \\
\text { (-50\% población pobre) }\end{array}$ & $\begin{array}{c}\text { Castilla-La Mancha } \\
\text { Madrid }\end{array}$ & $\begin{array}{c}\text { Castilla y León } \\
\text { Extremadura } \\
\text { Galicia }\end{array}$ \\
& & $\begin{array}{c}\text { Islas Baleares } \\
\text { Murcia }\end{array}$ \\
\hline
\end{tabular}

Fuente: Elaboración propia, a partir de Rodríguez Cabrero (cap.7) en EDIS (1998) op.cit.

Tabla 10.

Intensidades de pobreza, acceso a servicios y eficacia subjetiva.

\begin{tabular}{lccc}
\hline & $\begin{array}{c}\text { Tasa de Acceso a } \\
\text { Redes Públicas }\end{array}$ & $\begin{array}{c}\text { Tasa de Acceso a } \\
\text { Redes Asociativas }\end{array}$ & $\begin{array}{c}\text { Percepción de } \\
\text { Eficacia subjetiva }\end{array}$ \\
\hline Pobreza Severa & $45,2 \%$ & $52,8 \%$ & $15,0 \%$ \\
Pobreza Grave & $46,0 \%$ & $51,7 \%$ & $19,0 \%$ \\
Pobreza Moderada & $49,0 \%$ & $47,1 \%$ & $22,0 \%$ \\
Umbral de pobreza & $52,1 \%$ & $41,6 \%$ & $23,0 \%$ \\
\hline
\end{tabular}

Fuente: Elaboración propia, a partir de Rodríguez Cabrero (cap.7) en EDIS (1998), op.cit.

Cruz Roja, en detrimento de las públicas. A la vez, la población en pobreza severa expresa los porcentajes más bajos de percepción subjetiva de eficacia.

\section{Los Programas de Rentas Mínimas}

Más allá de las redes de servicios sociales, pero en estrecha relación con ellas, emerge en España, a finales de los años ochenta, un nuevo componente de política pública en el combate contra la exclusión: las rentas mínimas de inserción (RMI) 


\section{RIS}

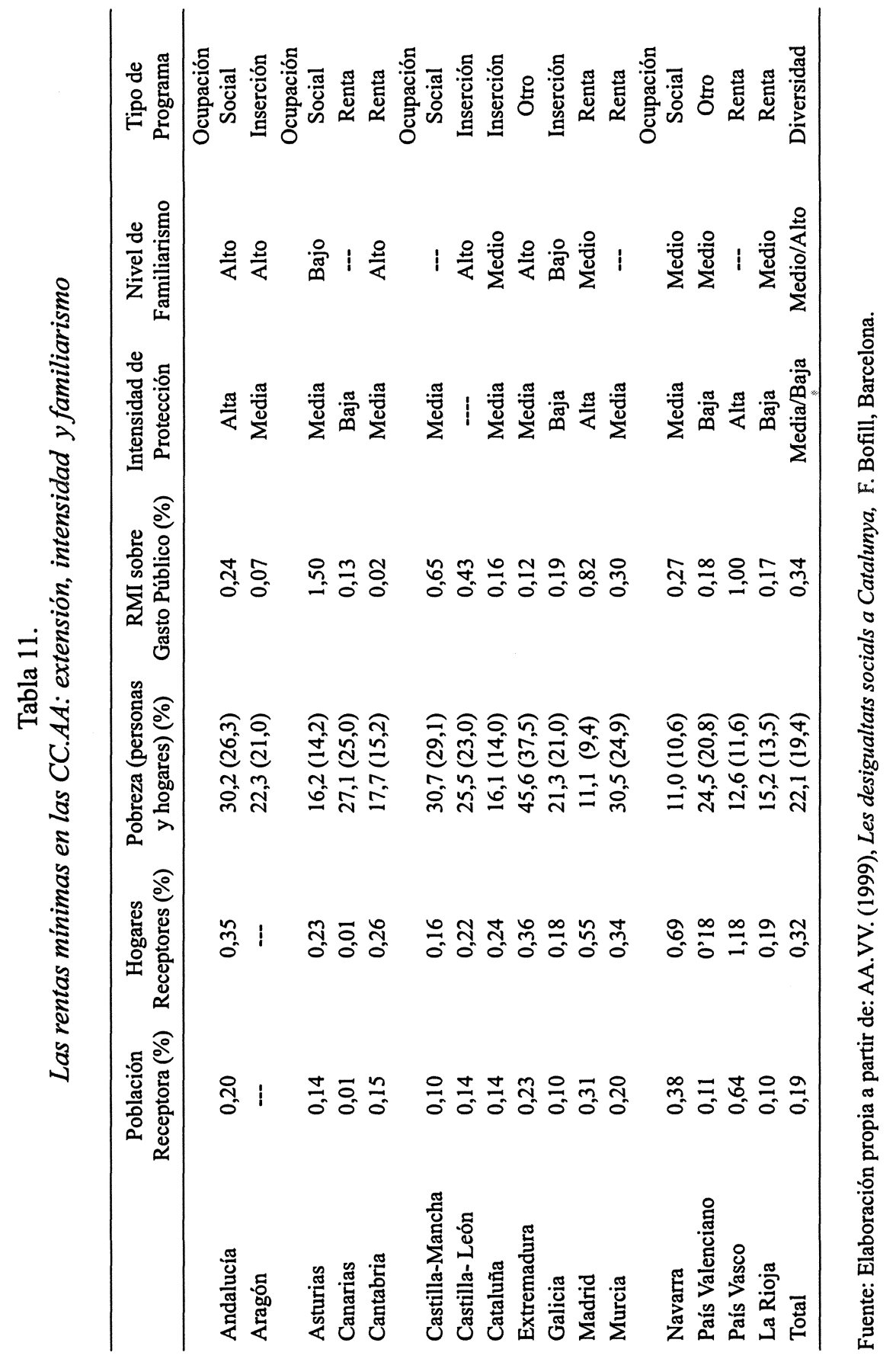


autonómicas (Ayala, 2000; Estévez, 1998). La tabla 11 expone las variables clave para caracterizar la diversidad entre CC.AA. de los programas de RMI. Las tres primeras columnas aportan información sobre el parámetro de extensión de la cobertura. Las dos siguientes aportan datos sobre el parámetro de intensidad protectora. La penúltima columna expresa la variación de la transferencia en función del tamaño del hogar receptor, lo que se convierte en un indicador clave del nivel de familiarismo implícito en la concepción de la política. Finalmente, se muestra el tipo de diseño: rentas mínimas clásicas con programas de inserción a posteriori, rentas mínimas condicionadas a itinerarios de inserción previamente definidos, y rentas mínimas que implican algun tipo de trabajo social u ocupación comunitaria.

En síntesis, puede observarse la baja extensión general de la cobertura: a las rentas mínimas accede sólo una minoría de la población pobre potencialmente activa; la baja intensidad protectora: en ninguna Comunidad Autónoma la cuantía de la RMI se situa por encima del umbral de pobreza a partir de dos personas en el núcleo familiar; el elevado familiarismo; y la voluntad innovadora en el diseño de los programas, intentado siempre la conexión a uno u otro tipo de trayectoria de incorporación laboral (Noguera y Ubasart, 2002; Serrano y Arriba, 1998).

\section{HACIA UNA NUEVA AGENDA DE POLÍTICAS PARA COMBATIR LA EXCLUSIÓN SOCIAL}

Sobre la base de todo lo tratado hasta aquí, se hace posible proponer una agenda integrada para la acción pública contra la exclusión social. Esta agenda se configura a partir de la toma en consideración tanto de los factores generadores de exclusión (apartado III), como de la matriz de colectivos vulnerables (apartado IV) y del análisis que deriva de las políticas contra la exclusión realmente existentes (apartado V). Se trata, en definitiva, de construir una agenda que aborde la exclusión social desde todas las dimensiones sectoriales y temáticas implicadas (tabla 12).

A lo largo del texto ha ido tomando forma una idea: la interrelación de la exclusión o la precariedad en el ámbito laboral y en el residencial (territorio y vivienda), con la imposibilidad práctica de acceso a los mecanismos públicos de protección e inserción social. Interrelación que configura las coordenadas vitales de una parte importante de la población socialmente excluida. Ante ello, el núcleo de la agenda contra la exclusión podría configurarse sobre la base de tres ejes. En primer lugar, el fortalecimiento del sistema de servicios sociales y rentas mínimas, que puede concretarse en dos direcciones: la universalización de los servicios y el avance hacia un modelo de rentas básicas garantizadas. En segundo lugar, la potenciación de las políticas activas contra la exclusión laboral y por la calidad 
R IS

REVISTA INTERNACIONAL DE SOCIOLOCIA

No 33, Septiembre-Diciembre, 2002

QUIM BRUGUÉ, RICARD GOMÀ y JOAN SUBIRATS

Tabla 12.

Agenda de Políticas contra la Exclusión Social.

AGENDA DE POLÍTICAS CONTRA LA EXCLUSIÓN SOCIAL

- Políticas de universalización de servicios sociales y rentas básicas

- Políticas contra la exclusión laboral y por la calidad del empleo

- Políticas de vivienda social y regeneración integral de barrios

- Políticas de ciudadanía e interculturalidad

- Políticas por la plena igualdad de género

- Políticas integrales de ciclo de vida: infancia, adolescencia y gente mayor vulnerable

- Políticas sociosanitarias

- Políticas educativas comunitarias e integrales

- Políticas contra la fractura digital

Fuente: Elaboración propia.

del empleo, desde formación e intermediación activa, hasta nuevos yacimientos y reparto del trabajo, pasando por la erradicación de los salarios bajos. En tercer lugar, una acción pública decidida a favor de la vivienda social, de la promoción pública de alquiler, de la rehabilitación y de la regeneración integral de los barrios degradados (Geddens Benington, 2002).

Más allá de este núcleo, algo así como una segunda corona en la lucha contra la exclusión debería incidir en otras tres zonas de alta vulnerabilidad social. Políticas de interculturalidad y plena ciudadanía de la población inmigrante; políticas contra la precariedad vital de las mujeres en el ámbito familiar, en el espacio público y en el mercado de trabajo; y políticas integrales de ciclo de vida (infancia, adolescencia y gente mayor en riesgo).

No podemos olvidar tampoco la dimensión anti-exclusión de los grandes servicios públicos universales: las políticas sociosanitarias y los proyectos educativos integrales, pensados y practicados desde la esfera local y la vinculación a la comunidad.

Por último, cabe incorporar hoy a la nueva agenda las políticas contra la fractura digital, tanto en clave social como territorial y, por tanto, todas aquellas estrategias orientadas a democratizar y universalizar la sociedad de la información.

\section{EL NÚCLEO DURO DE LA AGENDA CONTRA LA EXCLUSIÓN}

\section{La renta básica de ciudadanía}

$\mathrm{Al}$ inicio de este artículo sostuvimos que el creciente déficit de inclusividad del Estado de bienestar había operado como uno de los factores clave de generación 
de exclusión social. Déficit de inclusividad debido tanto a los cambios de fondo y acelerados en los principales parámetros de la sociedad industrial (diversificación étnico-cultural, envejecimiento y dependencia, nuevas formas de familia, empleo precario, paro de larga duración...) como a la relativa falta de voluntad política y capacidad de innovación colectiva para tratarlos en positivo.

El déficit de inclusividad no ha afectado por igual a todos los regímenes de bienestar europeos, ni éstos han respondido con el mismo enfoque e intensidad. En el campo de los sistemas públicos de garantía de rentas, pueden distinguirse en Europa tres grandes modelos de organización colectiva de la solidaridad.

a) El modelo continental o bismarckiano, consistente en asegurar a los trabajadores/as en caso de pérdida de ingresos, ya sea por salida coyuntural o permanente del mercado de trabajo. En él, las prestaciones son condicionales a la cotización previa. Es un sistema poco o nada redistributivo, esencialmente conectado al empleo y de raiz familiarista tradicional.

b) El modelo anglosajón o beveridge ofrece prestaciones monetarias a todas las personas que estén, de forma comprobada, por debajo de un determinado nivel de ingresos, pero no exige ningún tipo de cotización previa. Es un sistema más asistencial que redistributivo, dado el normalmente bajo nivel de las prestaciones. $\mathrm{Ha}$ tendido más al control y a la estigmatización de los beneficiarios que a la efectiva inclusión social de éstos.

c) El modelo escandinavo presenta un esquema de transferencias parecido al anglosajón, pero la protección social se realiza fundamentalmente por medio de un sistema universal de servicios públicos de alta calidad, articulados con fuertes políticas de empleo. Es el sistema más igualitarista y redistributivo. Sin embargo, no resuelve bien el problema de la pobreza y la exclusión cuando falla el pleno empleo.

d) El modelo latino-familiarista incorpora trazos del esquema continental, con mecanismos contributivos fuertes, aunque con tasas menores de sustitución de ingresos. Su especificidad radica en la enorme debilidad de las prestaciones asistenciales y de los servicios personales; en este terreno, la familia sigue siendo el principal - y a menudo único - resorte de bienestar.

¿Cómo han respondido estos tres regímenes de garantía de rentas a los déficit de inclusividad ?. Tal como se desprende de la revisión de políticas públicas realizada en los apartados anteriores, las respuestas han ido en dos direcciones principales. Por un lado, el fortalecimiento de las políticas activas, ya sea desde planteamientos de empleabilidad y workfare (Levitas, 1998), ya sea por medio de estrategias de reparto del trabajo y nuevos yacimientos de empleo. Por otro lado, se da el surgimiento general de las rentas mínimas de inserción (RMI), como safety net para ciertas personas y familias de bajísimo nivel de ingresos. Las dos vías implican avances, pero también presentan límites claros. Las nuevas políticas activas son palancas insuficientes para conseguir el pleno empleo. Tampoco ayudan a replantearse la validez del trabajo asalariado como eje de la ciudadanía social. Las nuevas RMI presentan bajos niveles de cobertura, no resuelven la 
vulnerabilidad al empleo en precario, son familiaristas y discrecionales. En definitiva, difícilmente se restablece el carácter inclusivo-cohesionador del Estado de bienestar.

Es aquí donde surge y cobra sentido la Renta Básica (RB), como nuevo instrumento de política pública universal, solidario, inclusivo y redefinidor de la ciudadanía social (Raventós, 1999, 2001; Noguera, 2000). La RB redefine estratégicamente la dimensión de transferencias del Estado de bienestar. Supera las tres filosofías preexistentes. Su objetivo es la desmercantilización de las personas: poder vivir dignamente, con independencia de la relación con el mercado de trabajo.

¿Cómo se define pues la RB?. La renta básica es un pago que los poderes públicos realizan mensualmente a cada persona residente en su territorio, de forma estrictamente individual, incondicionalmente -incluso si no se quiere trabajar de manera remunerada $-y$ con independencia de cualquier otro ingreso o fuente de renta que se pueda tener.

La renta básica es un instrumento flexible de generación de autonomía personal. Puede modularse su cuantía, estableciéndose una renta parcial que coexista con otras transferencias sociales, o bien haciéndola variable según la franja de edad. Puede modularse su universalidad, focalizándola en determinados colectivos, ya sea por razones de edad, de salida del mercado de trabajo o de exclusión de la cobertura contributiva. Finalmente, puede modularse su incondicionalidad, vinculándola a la realización de un determinado número de horas de trabajo socialmente útil a lo largo de la vida o de ciertos periodos de ésta.

Los impactos de la RB son muchos y complejos, pero merce la pena destacar los principales. En primer lugar, erradicaría la pobreza, no la exclusión social, pero sí la falta de ingresos como componente de la exclusión. En segundo lugar, podría tener unos efectos igualitaristas y de reducción de las desigualdades, tanto en el plano material, como en las esferas de género, familia y edad. En tercer lugar, al hacer a las personas menos dependientes del trabajo asalariado, la $\mathrm{RB}$ podría ser un factor de apoyo a las estrategias de reducción de jornada y de flexibilidad regulada. Desde luego, también podría provocar un incremento de dedicaciones a trabajos no asalariados: asunción de responsabilidades personales en espacios comunitarios, asociativos, domésticos etc., con el consecuente incremento de las tasas de capital social. Por último, la RB superaría lo que los autores anglosajones han llamado el poverty o unemployment trap, el círculo vicioso consistente en renunciar o aplazar la inserción laboral en la medida que el nivel de subsidios

\footnotetext{
${ }^{3}$ En cualquiera de los modelos actuales de garantía de rentas, las transferencias públicas son sustitutivas de los ingresos salariales. La RB no es sustitutiva, es acumulativa. Para hacer factible su financiación, se requiere -entre otras cosas- un profundo cambio en los sistemas contributivos, con el consiguiente traslado de recursos al sistema fiscal.
} 
condicionados es lo suficientemente elevado. Con la $R B$ esto no pasaría, ya que el ingreso por $\mathrm{RB}$ sería no condicionado, y por tanto, acumulable a cualquier otro ingreso derivado de la inserción laboral.

\section{Las políticas de inclusión en el empleo y la vivienda}

La plena inserción en los mercados de trabajo y de vivienda es hoy requisito indispensable para el desarrollo autónomo de proyectos vitales, al margen de riesgos más o menos sistemáticos de exclusión social. Ni el empleo ni la vivienda, a diferencia de la sanidad o de la educación, se han configurado como servicios desmercantilizados, prestados al conjunto de la ciudadanía por los mecanismos del Estado de bienestar. Ambos, además, están sometidos a fuertes presiones, derivadas de los impactos generados por los cambios económico-productivos y los cambios en el modelo urbanizador de las sociedades posindustriales. Dichos cambios generan más dosis de incertidumbre y más potencial de exclusión para ciertos colectivos altamente vulnerables, tanto al desempleo como a la marginación residencial. Por ello, consideramos que toda estrategia pública multidimensional frente a la exclusión debería incorporar - como uno de sus ejes centrales- políticas por la inclusión social en las esferas laboral y urbana (Littlewood et al., 1999).

\section{Políticas por la inclusión en la esfera laboral}

Conectadas al ámbito laboral, pueden distinguirse dos tipos de exclusiones sociales. Por una parte, la exclusión del mercado de trabajo, expresada en forma de dificultades intensas de inserción, expulsión y desempleo no protegido y de larga duración. Por otra parte, la exclusión en el mercado de trabajo, reflejada en la precarización múltiple del empleo y de las relaciones laborales. Ambos tipos de exclusión se focalizan de forma especial y más intensa en ciertos colectivos, definidos en función de sus bajos niveles educativos, de su origen u opción cultural, de su franja de edad, de su contexto familiar y relacional de género, y de su situación sociosanitaria. La tabla 13 muestra el mapa de colectivos que resulta de cruzar los dos tipos de exclusión laboral, con las circunstancias de riesgo citadas.

El cuadro del ANEXO 1 muestra el abanico de posibles políticas para hacer frente a las exclusiones en el ámbito laboral. En el eje vertical, los dos tipos de exclusión antes considerados se convierten ahora en los tres objetivos estratégicos a perseguir: garantizar niveles de calidad, generar procesos de inserción específicos, y ofrecer mecanismos sólidos de protección a los colectivos desempleados. En el eje horizontal, se distingue entre las políticas de sesgo más estructural, orientadas a debilitar los factores generadores de exclusión laboral, y las políticas de tipo preventivo y paliativo, focalizadas sobre los grupos de población que sufren de forma más directa las consecuencias de la exclusión en relación al empleo (Gallie y Paugan, 2000). 


\section{RIS}

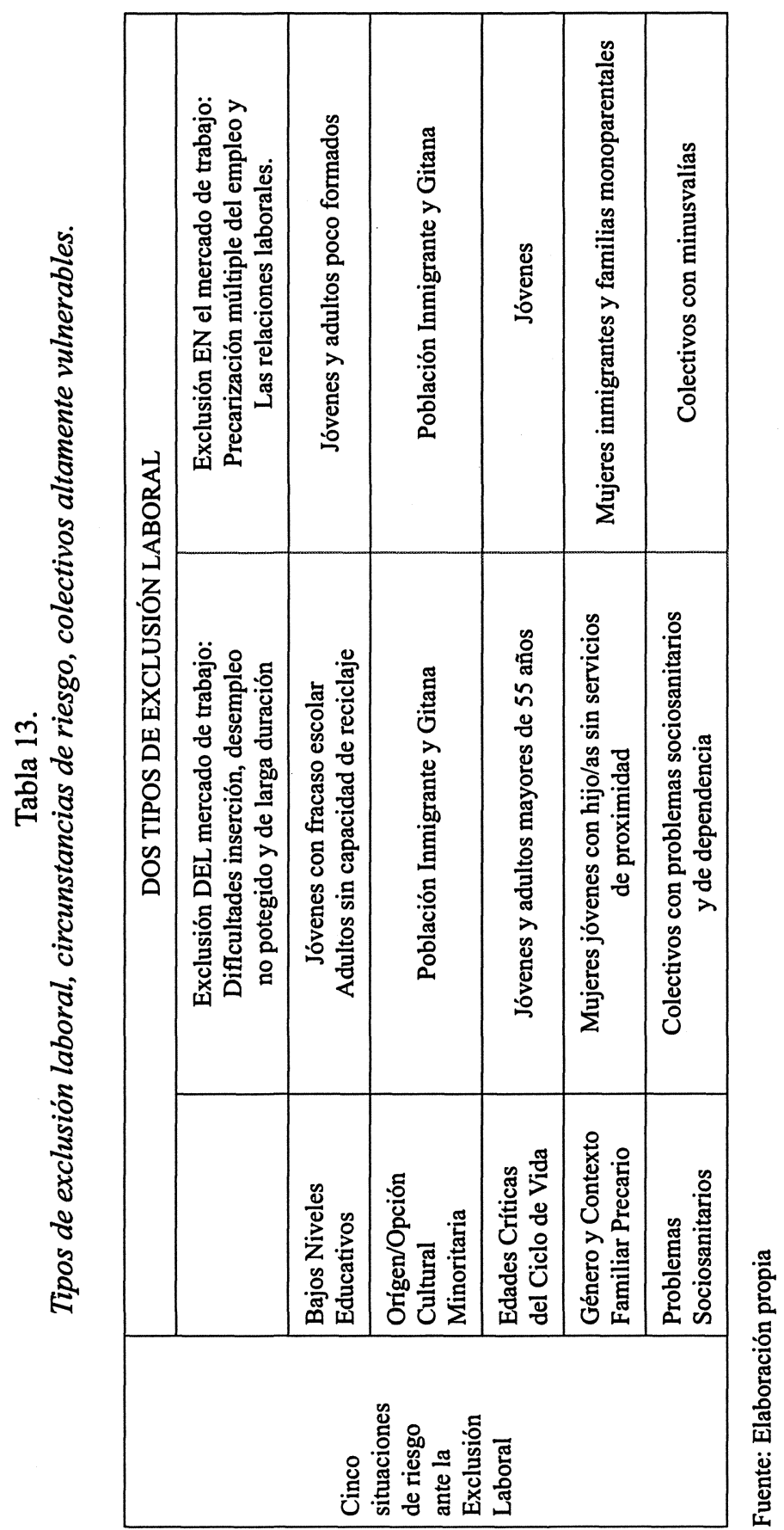




\begin{tabular}{|c|c|}
\hline DE LA POBREZA A LA EXCLUSIÓN SOCIAL & $\begin{array}{l}\text { REVISTA INTERNaCiONaL de SOCiOLocía } \\
\text { № 33, Septiembre-Diciembre, } 2002\end{array}$ \\
\hline
\end{tabular}

Politicas por la inclusión en la vivienda y el espacio urbano

En el ámbito de la vivienda y el espacio urbano, la exclusión viene generada por el carácter socialmente selectivo y segregador de los mercados de suelo e inmobiliario, con una presencia pública generalmente débil o residual. Se expresan tres tipos principales de exclusión. En primer lugar, la discriminación en el acceso y la posible precariedad económica producida por el peso excesivo del gasto en vivienda sobre las fuentes de la economía familiar. En segundo lugar unas pautas de residencia en condiciones de infravivienda (vivienda sin servicios y equipamientos básicos) y hacinamiento. En tercer lugar, las situaciones más duras de desigualdad urbana, es decir, el alojamiento en barrios sujetos a procesos de multidegradación. Igual que en la esfera laboral, estos tipos de exclusión se focalizan de forma especial y más intensa en ciertos colectivos, definidos en función de sus bajos ingresos, de su origen u opción cultural, de su franja de edad, de su contexto familiar y relacional de género y de su situación sociosanitaria (Mingione, 1996). La tabla 14 muestra el mapa de colectivos que resulta de cruzar los tres tipos de exclusión social urbana, con las circunstancias de riesgo citadas.

El cuadro del ANEXO 2 muestra el abanico de posibles políticas para hacer frente a las exclusiones en el ámbito urbano y residencial. En el eje vertical, los tres tipos de exclusión antes considerados se convierten ahora en los tres objetivos estratégicos a perseguir: corregir las discriminaciones de acceso, garantizar una vivienda en condiciones dignas y superar las pautas de segregación social de las ciudades. En el eje horizontal, se distingue entre las políticas de sesgo más estructural, orientadas a debilitar los factores generadores de exclusión urbana y las políticas de atención a colectivos y territorios en condiciones de marginación residencial.

\section{SÍNTESIS E INTERROGANTES FINALES}

En definitiva, después de todo lo visto, nos quedan algunas cosas claras y muchos interrogantes. Los procesos de inclusión y exclusión son sociales y no pueden reducirse a meras fórmulas sectorializadas. Son procesos de riesgo personal y colectivo. Son procesos muy vinculados al territorio más próximo. Son procesos en los que individuo, comunidad y relaciones sociales son elementos clave. Son procesos definitivamente participativos y abiertos. Pero, desde esta concepción, probablemente es necesario avanzar en temas que son hoy por hoy aún grandes interrogantes. ¿Lograremos ampliar nuestra concepción actual del trabajo, haciendo que vaya más allá de lo que hoy se considera empleo en una lógica de mercado? ¿Podremos configurar formas de trabajo social y familiar cuyo valor sea reconocido socialmente y sea retribuido como tal? Para poder avanzar hacia una concepción tan rica como la que aquí dibujamos de inclusión, ¿no sería nece- 
RIS

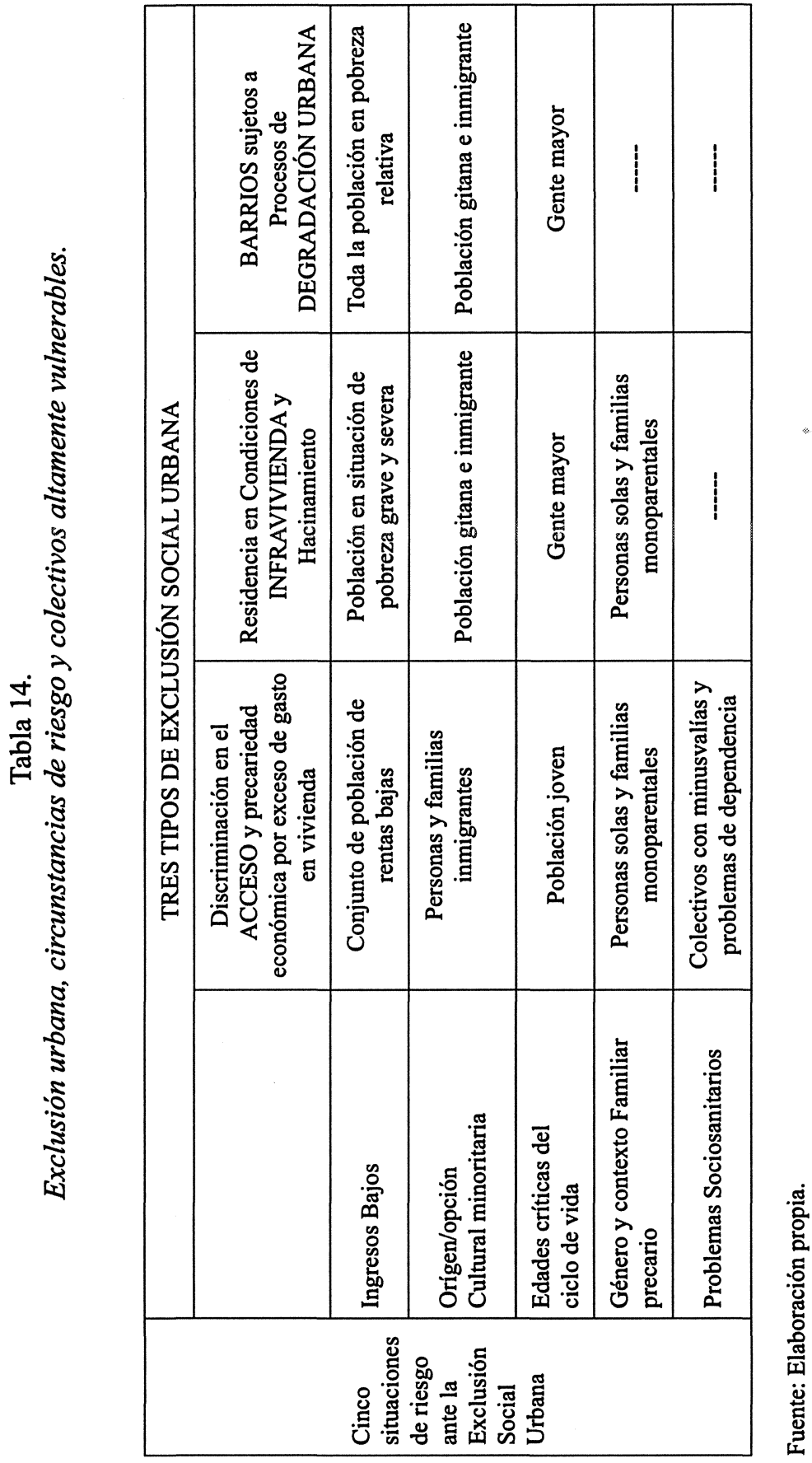

40 
sario disponer de un zócalo seguro como el que constituiría una renta de básica universal, como derecho de ciudadanía social, para poder garantizar una base vital a todos? Preguntas sin respuesta fácil, por ahora, pero que estan, pensamos, en la base de muchos de los temas que este artículo presenta con el ánimo, como siempre, de contribuir al debate académico.

\section{REFERENCIAS BIBLIOGRÁFICAS}

AA.VV. (1999), Les desigualtats socials a Catalunya, Barcelona, Fundació J.Bofill.

ADELANTADO, J. (ed) (2000), Cambios en el estado de bienestar, Barcelona, Icària.

ADELANTADO, J. y A. JIMÉNEZ (2002), "Las políticas autonómicas de servicios sociales", en R. Gallego, R. Gomà, J. Subirats (2002), Politicas sociales y descentralización en España, Madrid, Tecnos-UPF.

ATKINSON, T. (2002), Social Indicators. The EU and Social Inclusion, Oxford, Oxford University Press.

AYALA, L. (2000), Las rentas minimas en la reestructuración de los estados de bienestar, Madrid, CES.

BALDWIN, P. (1993), The Politics of Social Solidarity, Cambridge, Cambridge University Press.

BARNES, M. et al., (2002), Poverty and Social Exclusion in Europe, Edward Elgar, UK.

BAZAGA, I., J.A. RAMOS y M. TAMAYO (2000), "Pobreza y desigualdad en España: enfoques, fuentes y acción pública", Monográfico de la Revista Cuadernos de Gobierno y Administración Pública, $\mathrm{n}^{\circ} 2$.

BECK, U. (2002), Individualization, Londres, Sage.

BLANCO, I. y R. GOMÀ (2002), Gobiernos locales y redes participativas, Barcelona, Ariel.

BOMNES, M. y A. GEDDENS (2000), Immigration and Welfare. Ghanging the Borders of the Welfare State, Londres, Routledge.

CASTELLS, M. (1999), La era de la información, Madrid, Alianza Editorial.

CES (1997), La pobreza y la exclusión social en España, Madrid, CES.

COSIDINE, M. (2001), Enterprising states, Cambridge, Cambridge University Press.

EDIS (1998), Las condiciones de vida de la población pobre en España, Madrid, Foessa.

EDWARDS, R. y J. GLOVER (2001), Risk and Citizenship, Londres, Routledge.

ESTÉVEZ, C. (1998), Las Rentas Mínimas Autonómicas, CES, Madrid. 
RIS

EUROSTAT (1994), Panel de los hogares de la Unión Europea, Bruselas, UE.

GALLIE, D. y S. PAUGAN (2000), Welfare Regimes and the Experience of Unemployment in Europe, Oxford, Oxford University Press.

GALLEGO, R., R. GOMÀ y J. SUBIRATS (2002), Politicas sociales y descentralización en España, Madrid, Tecnos-UPF.

GARCÍA ROMERO, M.B. (1999), Rentas mínimas garantizadas en la UE, Madrid, CES.

GEDDENS, M. y J. BENINGTON (2002), Local Partnerships and Social Exclusion in the EU, Londres, Routledge.

GIL, F. (2002), La exclusión social, Barcelona, Ariel.

GOMÀ, R. y J. SUBIRATS (1998), Politicas públicas en España, Barcelona, Ariel.

(2001), Govern i politiques públiques a Catalunya, Barcelona, UAB/UB.

GOUL, J. y P. GENSEN (2002), Changing Labour Markets, welfare Policies and Citizenship, Bristol, The Policy Press.

HARRISON, M. y C. DAVIS (2001), Housing, social policy and difference, Bristol, The policy press.

HOOGHE, L (1996), Cohesion policy and European Integration, Oxford, Clarendon Press.

JANOSKY T. (1998), Citizenship and Civil Society, Cambridge, CUP.

KAUTTO, M. (2001), Nordic Welfare States in the EU Context, Londres, Routledge.

KICKERT, J. et al., (1997), Managing Complex Networks, Londres, Sage.

KLEINMAN, M. et al., (1998), European Integration and Housing Policy, Londres, Routledge. (2002), A European Welfare State?, Palgrave, United Kingdon.

LEVITAS, R. (1998), The Inclusive Society?, Londres, Macmillan.

LEWIS, J. (1998), Gender, Social Care and Welfare State Restructuring in Europe, Ashgate, UK.

LITTLEWOOD, P. (1999), Social Exclusion in Europe, Ashgate, United Kingdon.

MINGIONE, E. (1996), Urban Poverty and the Underclass, Oxford, Blackwell.

NOGUERA, J. (2000), “La renta básica garantizada y el estado de bienestar”, Revista Internacional de Sociologia, $\mathrm{n}^{\circ} 26$, pp. 65-95.

NOGUERA, J. y G. UBASART (2002), “Las politicas autonómicas de rentas minimas”, en 
Gallego, Gomà, Subirats (2002), Politicas sociales y descentralización en España, Madrid, Tecnos-UPF.

OCDE (1999), Social expenditure database, París, OCDE.

ÖSTERLE, A. (2001), Equity Choices and Long Term Care Policies in Europe, Ashgate, United Kingdom.

PERCY SMITH, J. (2000), Policy responses to social exclusion, Londres, Open University Press.

PIERSON J. (2002), Tackling social exclusion, Londres, Routledge.

RAVENTÓS, D. (1999), El derecho a la existencia, Barcelona, Ariel.

(2001 comp.), La renta básica, Barcelona, Ariel.

SAINSBURY, D. (1999), Gender and Welfare States Regimes, Oxford, Oxford University Press.

SARACENO, CH. (2002), Social Assistance Dynamics in Europe, Bristol, The Policy Press.

SERRANO, A. (1998), ¿Pobres o excluidos?. El Ingreso madrileño de Integración en perspectiva comparada, Madrid, Fundación Argentaria.

TEZANOS, J.F. (1999), Tendencias en desigualdad y exclusión social, Madrid, Sistema.

TORTOSA, J.M. (2001), Pobreza y perspectiva de género, Barcelona, Icaria. 
RIS

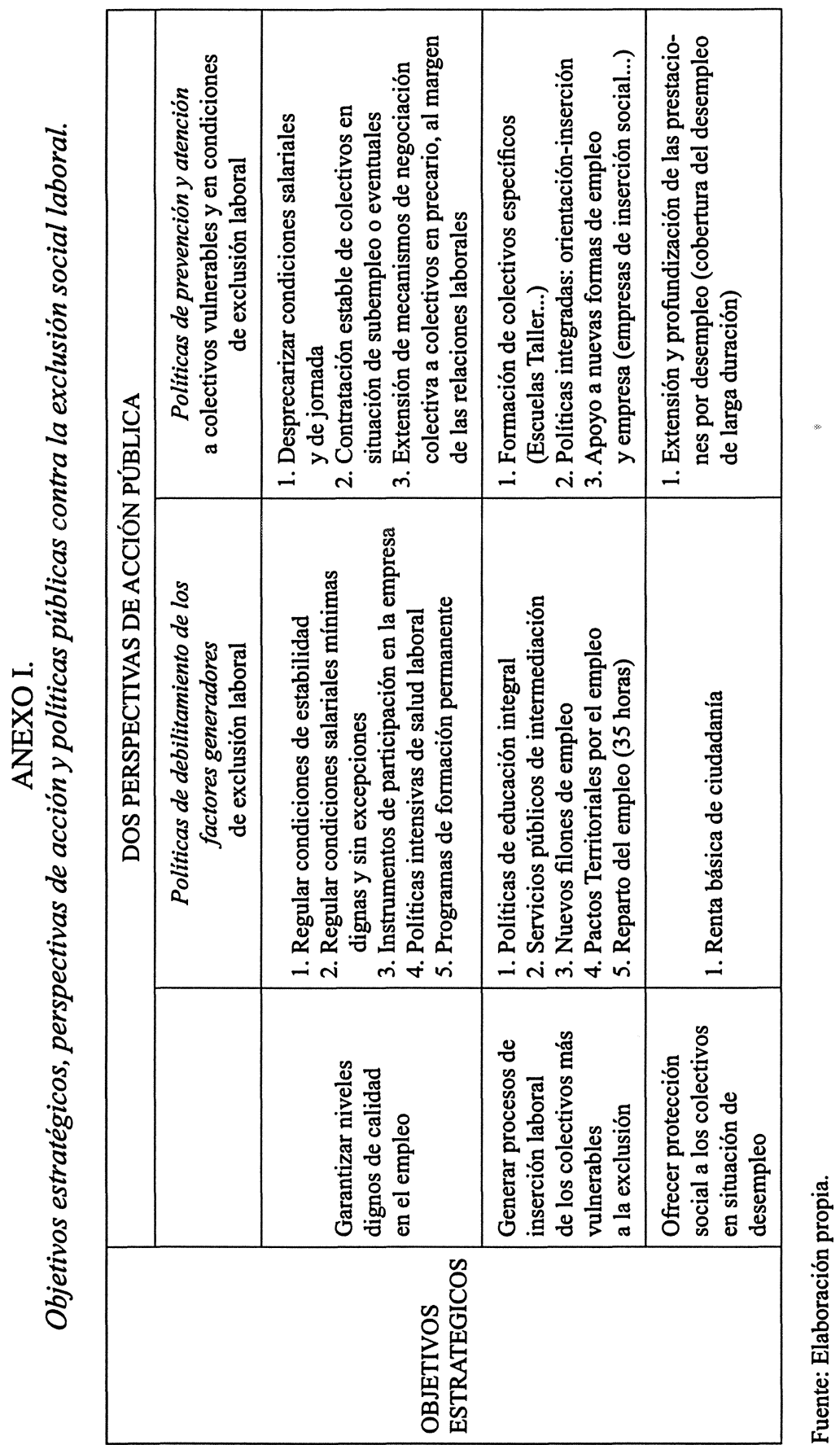

44 
RIS

REVISTA INTERNACIONAL DE SOCIOLOCIA

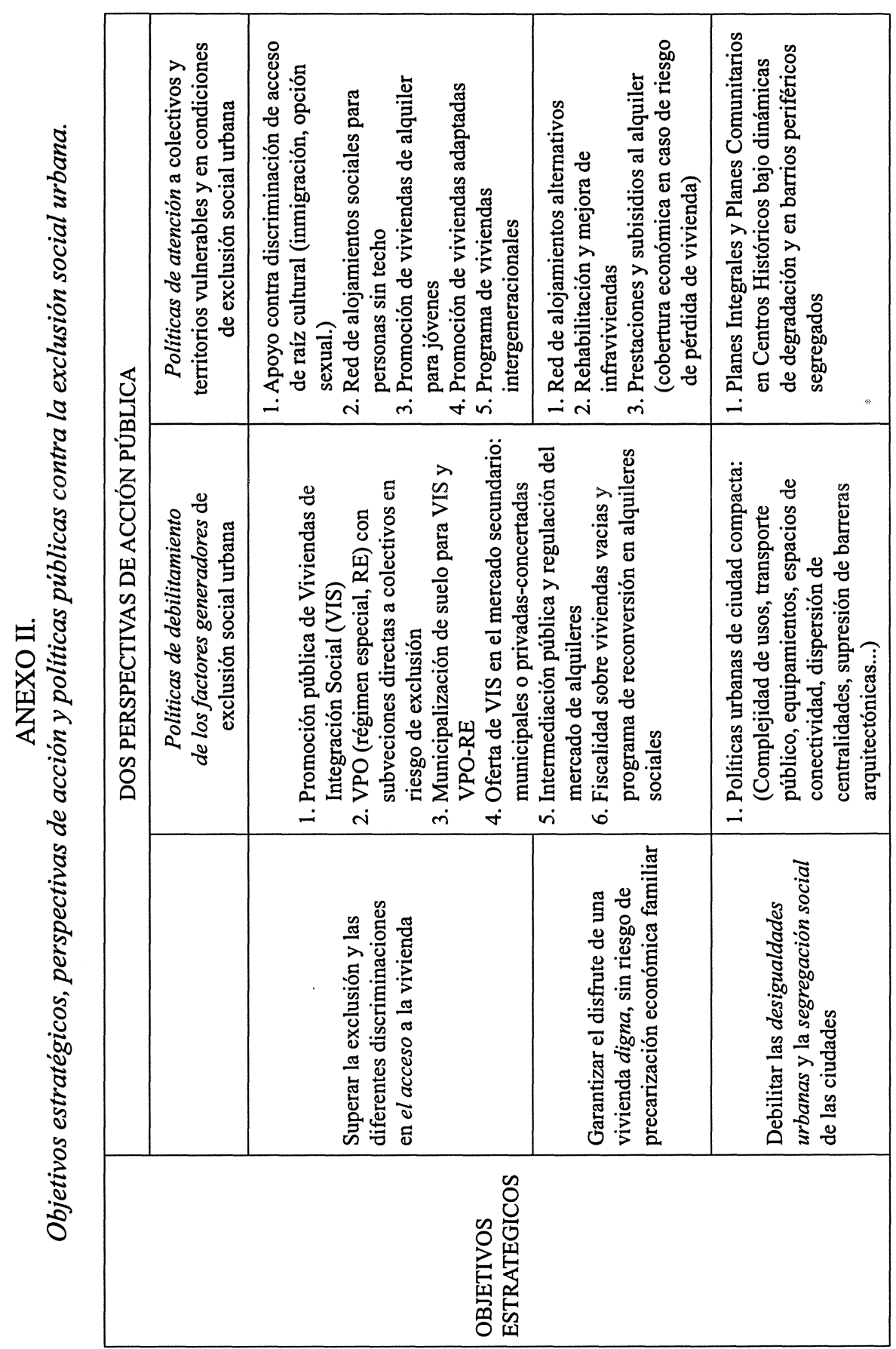

